RFP-2027

RFP-2027

August 2, 1973
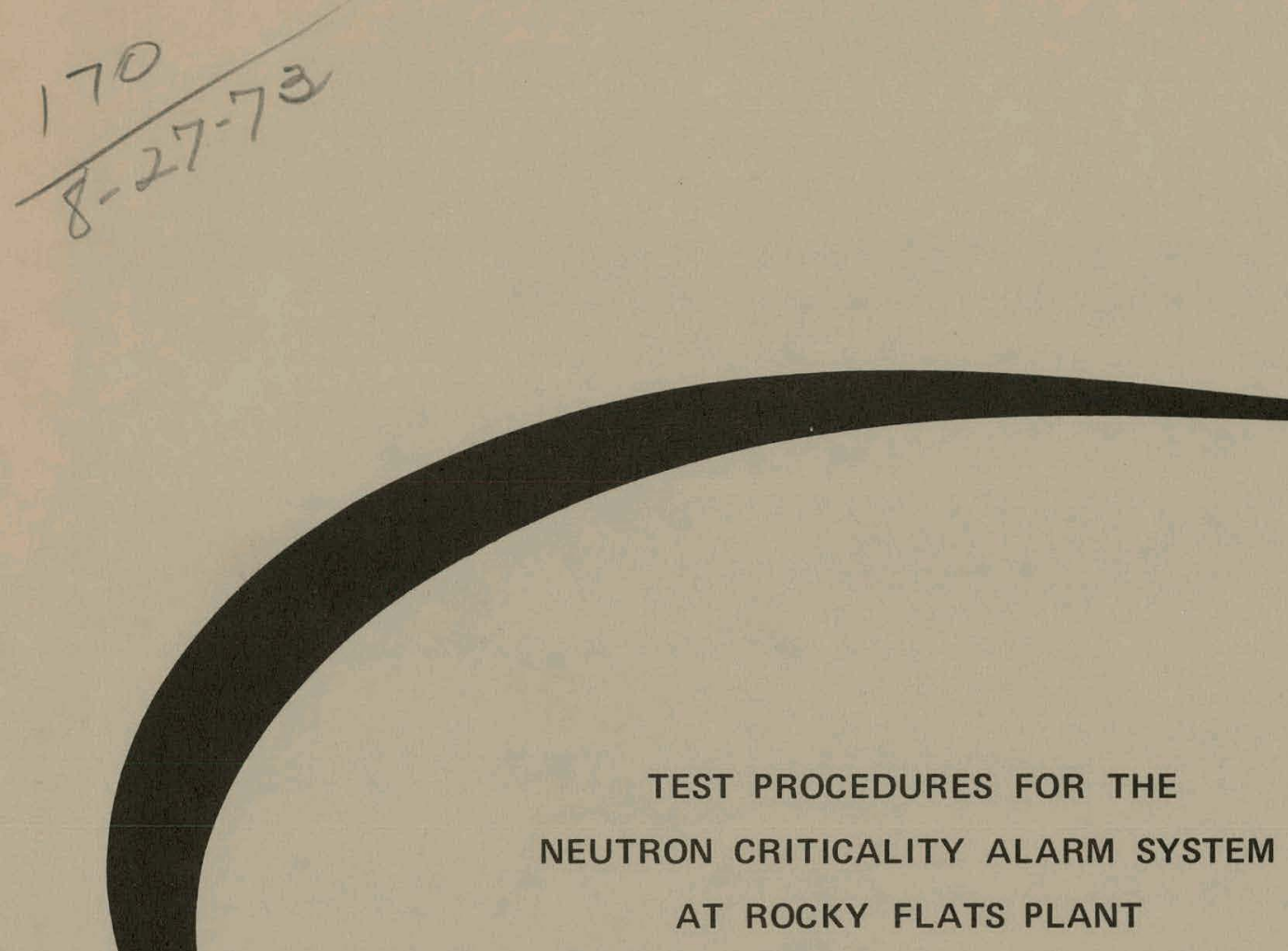

William H. Tyree

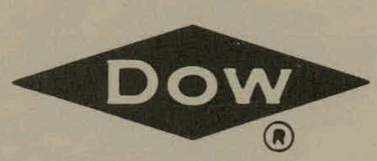

DOW CHEMICAL U.S.A. ROCKY FLATS DIVISION

P. O. BOX 888

GOLDEN, COLORADO 80401

U. S. ATOMIC ENERGY COMMISSION CONTRACT AT(29-1)-1106 


\section{DISCLAIMER}

This report was prepared as an account of work sponsored by an agency of the United States Government. Neither the United States Government nor any agency Thereof, nor any of their employees, makes any warranty, express or implied, or assumes any legal liability or responsibility for the accuracy, completeness, or usefulness of any information, apparatus, product, or process disclosed, or represents that its use would not infringe privately owned rights. Reference herein to any specific commercial product, process, or service by trade name, trademark, manufacturer, or otherwise does not necessarily constitute or imply its endorsement, recommendation, or favoring by the United States Government or any agency thereof. The views and opinions of authors expressed herein do not necessarily state or reflect those of the United States Government or any agency thereof. 


\section{DISCLAIMER}

Portions of this document may be illegible in electronic image products. Images are produced from the best available original document. 


\section{LEGAL NOTICE}

This report was prepared as an account of work sponsored by the United States Government. Neither the United States nor the United States Atomic Energy Commission, nor any of their employees, nor any of their contractors, subcontractors, or their employees, makes any warranty, expressed or implied, or assumes any legal liability or responsibility for the accuracy, completeness or usefulness of any information, apparatus, product or process disclosed, or represents that its use would not infringe privately owned rights.

Printed in the United States of America

Available from the

National Technical Information Service

U. S. Department of Commerce

Springfield, Virginia 22151

Price: Printed Copy $\$ 4.00$ Microfiche $\$ 0.95$ 
TEST PROCEDURES FOR THE

\section{NEUTRON CRITICALITY ALARM SYSTEM}

AT ROCKY FLATS PLANT

William H. Tyree

Research and Ecology

HEALTH PHYSICS RESEARCH GROUP

\section{NOTICE}

This report was prepared as an account of .work This report was prepar States Government. Neithes sponsored by the Un United States Atomic Energy the United States nor Commission, nor any of their employees, nor any of their contractors, subcontractors, or their employes, makes any warranty, express or implied, or assumes any legal liability or responsibility for the accuracy, completeness or usefulness of any information, apparatus, product or process disclosed, or represents that its use would not Infringè privately owned rights.

DOW CHEMICAL U.S.A.

ROCKY FLATS DIVISION

P. O. BOX 888

GOLDEN, COLORADO 80401

Prepared under Contract AT(29-1)-1106

for the

Albuquerque Operations Office

U. S. Atomic Energy Commission

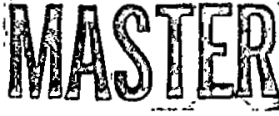


RFP-2027 


\section{CONTENTS}

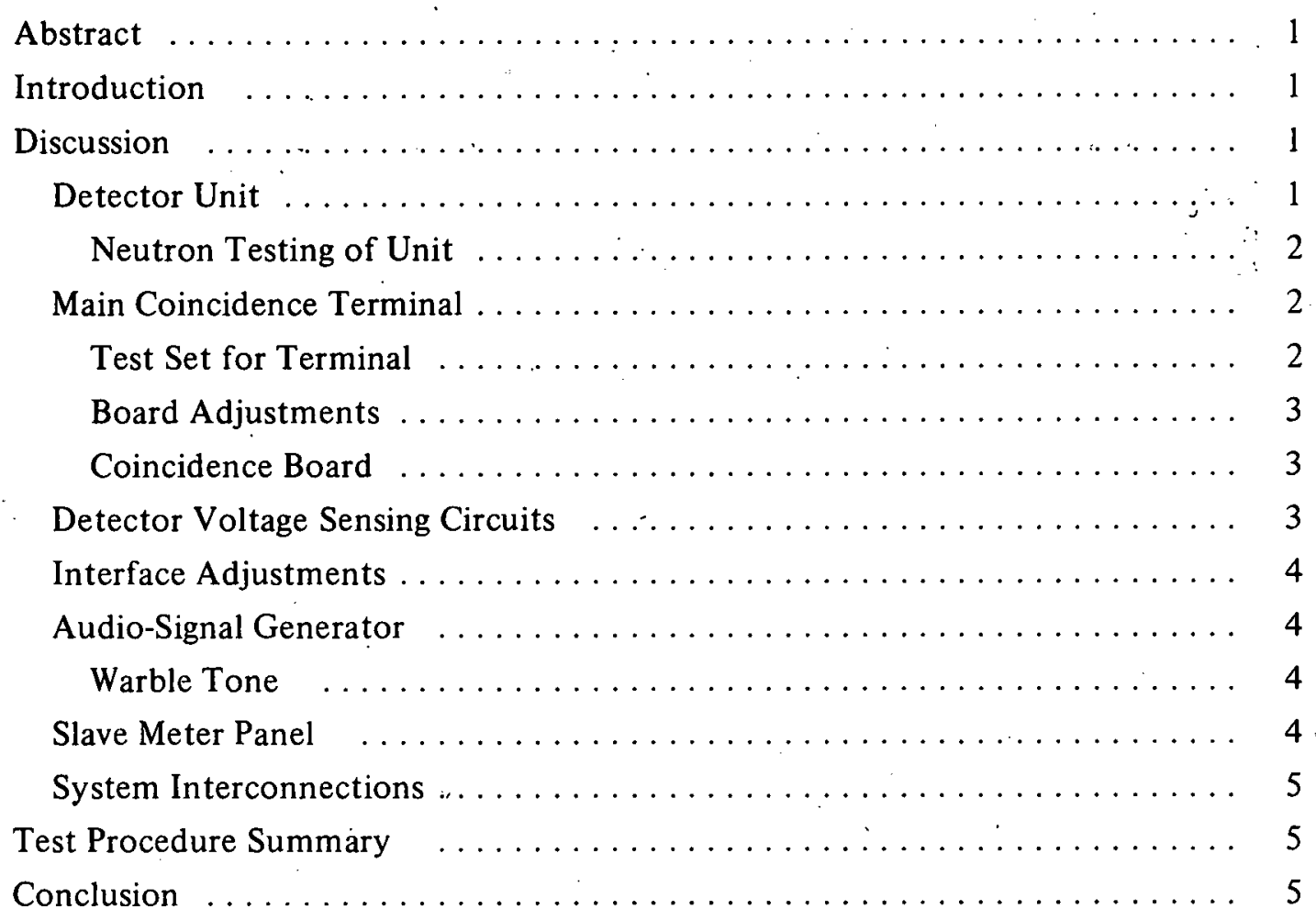

Figures 1 through 46

7 through 35 
ACKNOWLEDGMENTS

The author expresses thanks to members of the Health Physics Electronics Group for their interest and concern in providing a critique of the test procedures used in the Criticality Alarm System. B. E. Martin of the Electronics Group provided the design and development of the neutron system test set. 


\title{
TEST PROCEDURES FOR THE NEUTRON CRITICALITY ALARM SYSTEM AT ROCKY FLATS PLANT
}

\author{
William H. Tyree
}

\begin{abstract}
Test procedures are described of the Criticality Alarm System in use at the Rocky Flats Plant in Golden, Colorado. The purpose of the alarm system is to detect high levels of neutron radiation.
\end{abstract}

To assure effective use of the system in setting up operating parameters, circuit drawings together with photographs show component labels, controls, and related equipment units. All data have been taken from prepared Dow Drawings, Series No. 11962. Included are details of the electronics and radiation tests required to insure reliable alarm operation of the criticality detection system and interfaces.

\section{INTRODUCTION}

Under routine plant operations related to the handling of nuclear materials, systems of detection and control are constantly checked and improved to provide the maximum protection of personnel and plant facilities. The current report describes the modifications and improved test procedures developed to assure the maximum results from the Criticality Alarm System. An earlier report described the basic system and its components. ${ }^{1}$

Contained herein are the detailed procedures required for the proper operation of the detectors, main coincidence terminal, and interfaces.

\section{DISCUSSION}

The neutron alarm system includes two primary functions: First, a sensing unit which detects

\footnotetext{
'William H. Tyree. A Neutron Criticality Detection System. RFP-1621. Rocky Flats Division, Dow Chemical U.S.A., Golden, Colorado. March 21, 1973.
}

neutrons and produces a low voltage condition indicating a high level of neutron flux; Secondly, a terminal unit which senses the voltage condition present from all of the detector units and produces relay contact closures for actuation of various alarms, when any two detectors produce low voltage conditions. A block diagram of the system is shown in Figure 1. (See illustrations at end of text.)

\section{Detector Unit:}

The detector unit is shown physically and schematically in Figures 2 and 3. The various inside sections of the unit are noted in Figure 4.

In Figure 4, the amplifier-trigger board (00112) (a) on the left behind the bulkhead holds the test connector (BNC). Board 00106B (b) is located on the right between the second bulkhead and the chassis end holding the jack, switch, and UHF connector. Figure 5 shows the components or types of foils required to detect neutrons. The surface barrier detector (ND1) (c) produces electrical pulses from the alpha particles coming from the lithium fluoride $\left({ }^{6} \mathrm{LiF}\right)$ foils (d) (ND2). Only one foil and one detector are required to be mounted on Board 00112 (a) within the detector unit. The round foil (d) has a.stainless steel backing with the ${ }^{6} \mathrm{LiF}$ evaporated on the surface. The rectangular foil (d) was made from aluminum with sputtered ${ }^{6} \mathrm{LiF}$.

Figure 6 shows Board 00112 with the mounted foil (d), detector (c), and circuit board (a).

Figure 7 shows Board 00106B with the associated circuitry. Figure 8 shows the BNC test pulser used to set up the input-pulse sensitivity of the electronic amplifier-trigger board (00112). The controls of the pulser are set at the position to obtain monostable output from Board 00112. 
The detector unit must be set to provide for the detection of the electrical pulses in the surface barrier detector (ND1) from neutron-alpha interactions in the ${ }^{6} \mathrm{LiF}$ foil (ND2).

The detector unit must have an electronic pulser with a positive voltage output. A square-wave shape is satisfactory for the input pulse shape. The amplitude of the input positive pulse for producing an output square wave from the amplifier-trigger board (00112) at the collector of Q1 should be between 11 and 12 millivolts.

The trigger-voltage amplitude to the monostable multivibrator is adjusted by the potentiometer (R6) (see Figure 9). The potentiometer as viewed from the back of the unit is turned counter-clockwise to produce better sensitivity. The pulse width obtained from the monostable (collector of Q1) is approximately 10 microseconds. Inspection of the pulse amplitude at Q1 noted in Figure 10 with an input pulse to the test $\mathrm{BNC}$ will produce a small positive trigger pulse present at the collector of $Q 1$ just before the monostable triggers. Figure 11 shows the readout of a high pulse rate with the potentiometer (R6) set to produce half-triggered and halfuntriggered monostable operation.

The Q1 component should be a 2N4124 transistor instead of a $2 \mathrm{~N} 4123$ to insure a beta value of 100 or greater. Any general purpose transistor (NPN) having' a beta of 100 or greater is suitable. This value of beta insures the reset capability of the detector unit over long lines (500 feet or greater) and immunity to self triggering.

The pulse period of the reset monostable is adjusted by setting R19 on Board 00106B (see Figure 12). This should provide a reset period of approximately one second ( 0.9 to 1.1 seconds) between pulses produced by the monostable multivibrator at Pin 14 of the integrated circuit-2 (IC2). The pulse width at Pin 14 of IC 2 is approximately 5 microseconds positive polarity (Figure 13).

The sampling.generator circuit is disabled by inserting a 3-circuit plug into the test jack (arrow) located on the outside end of the detector unit (Figure 14). This connects the 10,000-ohm resistor, $\mathrm{R} 16$, to the positive DC voltage line and latches the voltage at Pin 14 of IC2 to ground level.
A normally closed push-button switch should be included in the plug-shorting circuit to eliminate accidental resetting of the silicon-controlled rectifier (SCR) when the plug is removed.

A series of three pulses within one second is normally required to produce triggering of the monostable with an output of the two-input gate of the MC717P (IC3). The pulse width of the monostable in IC3 produces a 50-microsecond positive pulse as noted in Figure 15:

NEUTRON TESTING OF UNIT - The disabled condition of the sampling generator can be used to permit a low-flux neutron source to trigger the SCR output of the detector unit. As a result of the disabling of the reset generator, the two-stage J-K flip-flop IC4 (MC776P) stores the three pulses in an indefinite period of time. A source of unmoderated plutonium fluoride ( $\mathrm{PuF}$ ) having an output of $10^{5}$ neutrons per square centimeter per second produces SCR triggering within one minute. Figure 16 shows a small source (arrow) positioned under the detector with the system untriggered.

\section{Main Coincidence Terminal:}

The second part of the test procedures includes descriptions of test equipment, and procedures required to set up the coincidence terminal and interfaces.

Figure 17 shows the block diagram of the coincidence terminal unit and its interfaces. Figures 18 and 19 show a typical 18 -detector terminal.

TEST SET FOR TERMINAL - A test set for making adjustments on the main terminal has been used to facilitate the setup. Included are a tworange volt meter and an adjustable $100-$ ohm potentiometer for setting input voltage levels at the input of the coincidence board and to the interface board. The unit is described in Figures 20, 21, 22, and 23 .

If the test set shown in the preceding figures is not available, the terminal may be set up with a multimeter capable of reading voltage, two grounding 
clip leads, and a 100-ohm potentiometer with clip. leads to the center and one end of the potentiometer. The voltage drop presented to the system by the triggered SCR in the detector unit may be simulated with a $15-\mathrm{ohm}$ resistor. Two of these are required to fulfill the two-unit coincidence requirement of the coincidence input circuits.

The 15-ohm resistor and $100-0 h m$ potentiometer are shown in Figures 24 and 25, respectively.

BOARD ADJUSTMENTS - Figure 26 shows the circuit diagram in a single coincidence board for a 6-detector system. Systems with a larger number of detectors will require additional coincidence boards. The output of the IC on each of the coincidence boards must be tied together at the junction of the output of the $3.6-\mathrm{K}$ resistors and $R 49(K=1000)$. Usually only a single $S C R$ is required. If more than one SCR circuit is desired, two SCR Zener circuits may be built on two coincidence boards in the terminal unit.

COINCIDENCE BOARD - The system should have a normal DC voltage ( 8.3 to 8.5 volts). from the AC power supply and normally functioning battery supplies (6.2 volts). The system can be adjusted with the AC-switch located on the printed circuit board mounted on the power supply off and the battery supply providing normal terminal operation. If the terminal unit is connected to a set of detector units, all units must be in normal unalarmed condition.

\section{Detector Voltage Sensing Circuits:}

The adjustable trigger circuits for detector sensing and the output SCR circuits must be set with the following procedures to obtain reliable operation.

Use the neutron system test set or a 100-ohm potentiometer with separate test leads soldered to the center terminal and one end. Clip these leads to a detector input and to any ground on the alarm system. Adjust the potentiometer to produce 2.0 volts with the system in battery operation mode as shown in Figure 27. Adjusting the potentiometer in the input trigger circuit (typically $\mathrm{R} 4, \mathrm{R} 11, \mathrm{R} 18$, $\mathrm{R} 29, \mathrm{R} 36, \mathrm{R} 44$ ) will produce an output voltage of 4.5 volts or greater from its corresponding output voltage of 4.5 volts or greater from its corresponding output of the integrated circuit (see Figure 28). Measure the voltage ( 4.5 volts or greater) at the anode side of the $O R$ gate diode connected to the terminal of the integrated circuit as noted in Figure 29. Repeat the steps for each of the other detector inputs to the coincidence circuits.

The trigger circuit (R 53) as shown in Figure 30 for control of SCR output circuit should then be set to trigger at an input voltage of 1.7 volts. This is accomplished by shorting any one of the detector input circuits to ground with a test lead. Set the output voltage produced at R49 to 1.75 volts. The measurement is made at the junction of the resistor elements of the $O R$ gate (typically R6, $\mathrm{R} 13, \mathrm{R} 20, \mathrm{R} 31, \mathrm{R} 38, \mathrm{R} 46$ ) and the potentiometer $\mathrm{R} 49$. The voltage at R49 shown in Figure 31 must be set without the SCR trigger circuit activated. Adjust (R53) Figure 30 to just produce master-alarm circuit operation with 1.7 to 1.75 volts present at R49.

Reset the SCR output circuit several times to insure that the circuit will continue to produce reliable SCR gating. The voltage at $\mathrm{R} 49$ will decrease slightly when the SCR turns $O N$ because of increased load, a normal reaction.

While the single-detector input remains grounded, adjust R49 (Figure 31 ) to produce 0.95 volts. This sets the proper voltage level for two-detector operation of the output SCR trigger circuit. This voltage is also measured at the $O R$ gate junction output and potentiometer R49. The batteries must be at full charge.

When the AC switch on the Power Supply circuit board is turned $O N$, the voltage at the junction of the $O R$ gate and potentiometer $\mathrm{R} 49$ will raise from 1.2 to 1.3 volts, also a normal reaction.

The final test of the system requires two test-clip leads. These are connected between any two detector inputs and ground. 
Produced will be an output alarm condition (main alarm relays actuated and master meter reading LOW). The result must be true for either battery or AC operation mode for correct terminal operation. Remove all test components and return system to normal operation. This completes the terminal coincidence board setup.

\section{Interface Adjustments:}

After the coincidence board adjustments have been made, the interface adjustments can be made to Board 00157 . The schematic of the board is shown in Figüre 32.

The six potentiometers control the turn $O N$ point of the 6 sets of transistors. These circuits produce an equivalent Zener operation as a series gate to the output transistors controlling the individual interface relays. As shown in Figure 33, the input voltage level to each of the interface Zener circuits (arrow) is set to 3 volts. Set the potentiometer, as shown in Figure 34, for that input to just produce relay operation. This can conveniently be set by listening to the relay-change position while changing the position of the potentiometer.

\section{Audio-Signal Generator:}

The schematic of the generator is given in Figure 35, and the block diagram in Figure 36. The unit as noted in Figure 37 is normally mounted in the audio-amplifier rack. The circuit consists of two separate signal generators. One produces a squarewave output simulating the Klaxon horn. The other produces a warbling or yelping output which is distinctive to insure recognition as a criticality alarirm sound, apart from the normal sounds and noise levels in a production building.

The Klaxon simulator portion of Board 31700238A shown in Figure 38 consists of a square-wave astable multivibrator operating at approximately 150 hertz and an output control gate. A front panel meter (see Figure 37) is included to indicate the presence of the square-wave output from the astable multivibrator. The circuits involved on the circuit board for the Klaxon simulator are IC, Q1, and Q2. The frequency of the astable is controlled by $\mathrm{R} 1$.
WARBLE TONE - The circuit board is capable of providing a variable frequency oscillation prodúcing an aural warble or yelp. The basic circuit has the form of a blocking oscillator driven by a square: wave multivibrator operating at approximately a one-second repetition rate. The upper frequency produced by the blocking oscillator is determined by R.28. The output lovol may bc adjustcd with $\mathrm{R} 14$. The circuits involved in the warble generator are Q4, Q5, Q6, Q7, Q8, Q9, and Q2 as shown in Figure 39.

The signal gencrator shown in Figure 40 is mounted in the audio-amplifier rack. The nutpilt gate is controlled by the 24-volt key line to Pin 1 of the front terminal strip on the signal generator.

The signal generator operates from +24 volts DC available from the +24 -volt power supply of the Dukane Amplificr. The signal generator includes a series regulator to produce 7.6 volts for operation of the circuit board. The power-amplifier mounting rack contains the key linc to the main dispatcher control panel in the building.

The audio-output line from the signal generator is $600 \mathrm{ohms}$ of balanced output suitable for the Dukanc preamplifier input. 'The terminal strip shown in Figure 41 provides the interconnection point for the key-line uperalion of the audio-: generator, +24-volt distribution and preamplifier input. Usually these connections are not involved in normal system maintenance. The two relays shown in Figure 41 are used to provide supervised line conditions on the lelephone lines to the plant dispatcher.

Figure 42 shows the front panel of the rack holding the signal generatur, preannplifier, and distribution amplifiers. Access to the front or rear interior of the rack is controlled by lock and key.

\section{Slave Meter Panel:}

Figures 43 and 44 show a typical 18-detector slave meter panel which provides detector readout in a specific guard post. The system also includes (but not shown in the figure) a single detector and alarm in the upper left-hand corner of the meter panel. The alarm is dependent upon the relay 
operation associated with Board No. 00157. The alarm produces an $O N-O F F$ high frequency audio signal.

\section{System Interconnections:}

Figure 45 describes the interconnections to the printed circuit boards that make up the Main Display Panel. These interconnections show the interrelationships between the various operations in the system.

The alarm interfaces are shown in Figure 46. These connections provide multiple readout to various annunciators throughout the individual building and the plant site.

Relay K 5 shown in Figure 46 provides normally closed contacts for continuous supervised operation of the telephone lines between an individual building and central control. The relay cannot be removed from its socket without producing a building alarm.

The system provides readout to the following types of annunciators, outside beacons, plant dispatcher printer, aural alarm to the building public address system, and local guard-post visual and aural alarm for one or more detectors. The system is tested monthly to assure all interface operations and the response of all detectors to a neutron source.

\section{TEST PROCEDURE SUMMARY}

1. Detector Unit:

Test BNC, positive 11 to 12 millivolts, 3 pulses per second

- Output (00112), 2 volts, 10-microseconds positive

Reset Generator, 5 microseconds, 1 -second period

Neutron Source, $10^{5}$ neutrons per square centimeter per second $\left(\mathrm{n} / \mathrm{cm}^{2} / \mathrm{sec}\right)$, triggered in less than 1 minute with reset generator disabled
2. Coincidence System (00108G):

AC operation

AC power supply

$100-\mathrm{ohm}$ potentiometer, 2 volts at detector input

Produces 4 or more volts at integrated circuit (IC) output

Do all other 5 inputs

Set R49 to 1.7 volts with one input grounded

Set R53 to just produce silicon controlled rectifier (SCR) trigger (listen for relay operation)

Set $\mathrm{R} 49$ to 1.25 volts (AC operation)

Turn $O F F$ AC supply with single detector grounded

Voltage at R49 should be 0.95 volts (batteries must be fully charged)

3. Interface Board (00157):

Set test set or $100-0 h m$ potentiometer to produce 3 volts

Adjust each input potentiometer to produce relay operation

Do all 6 inputs

\section{CONCLUSION}

The test procedures were developed to insure reliable operation of the Neutron Criticality System presently in use at the Rocky Flats Division of the Dow Chemical Company U.S.A.

Additional questions or comments about the procedures or equipment may be obtained by writing or calling the author. 
RFP-2027

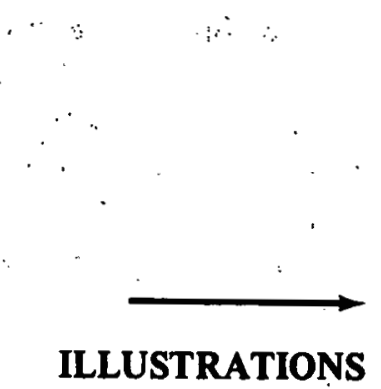

Figures 1 through 46 


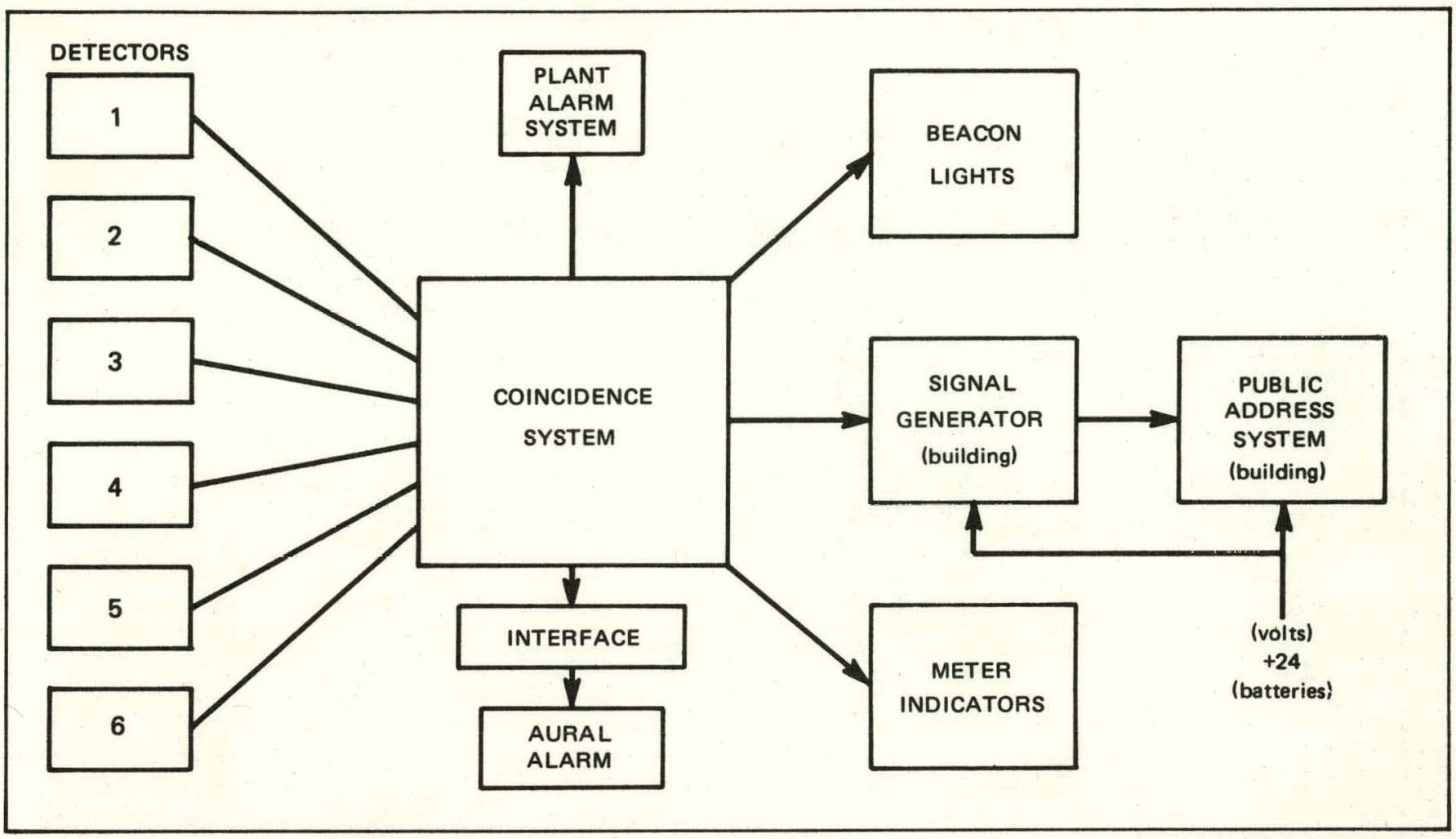

FIGURE 1. Block Diagram of System.

FIGURE 2. Neutron Detector Unit.

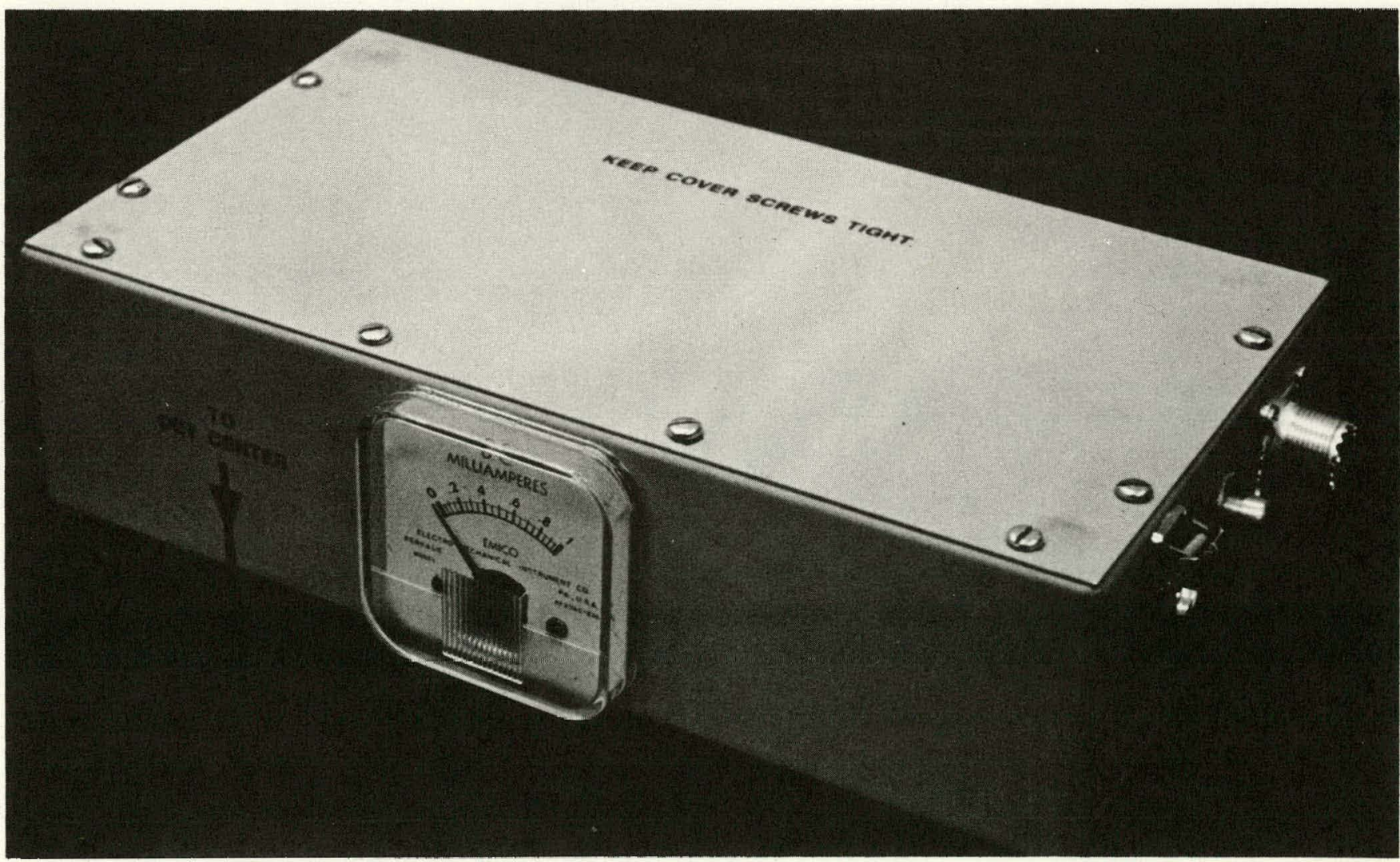


FIGURE 3. Schematic and Block Diagram of Detector Unit.

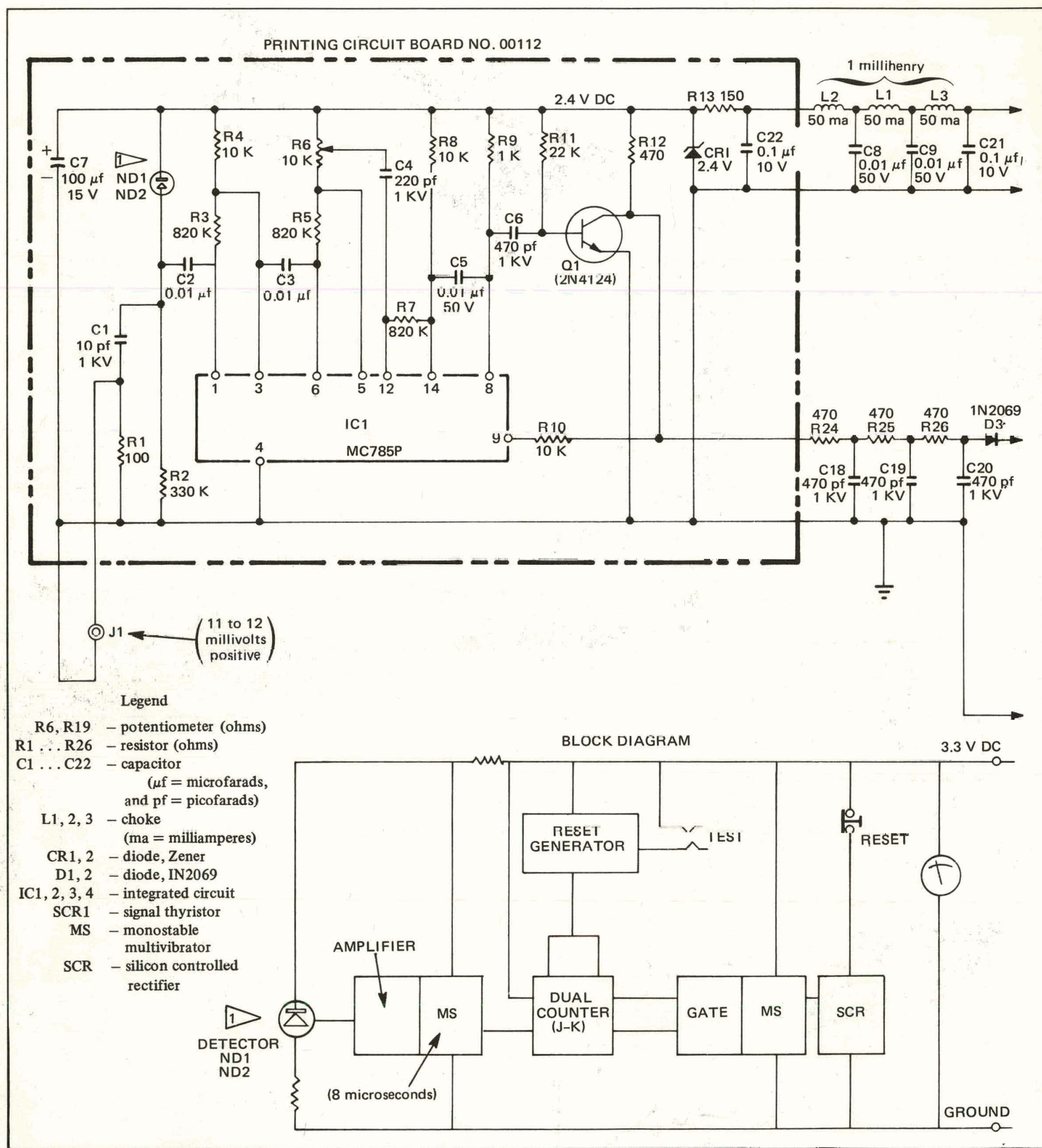


FIGURE 3. (continued).

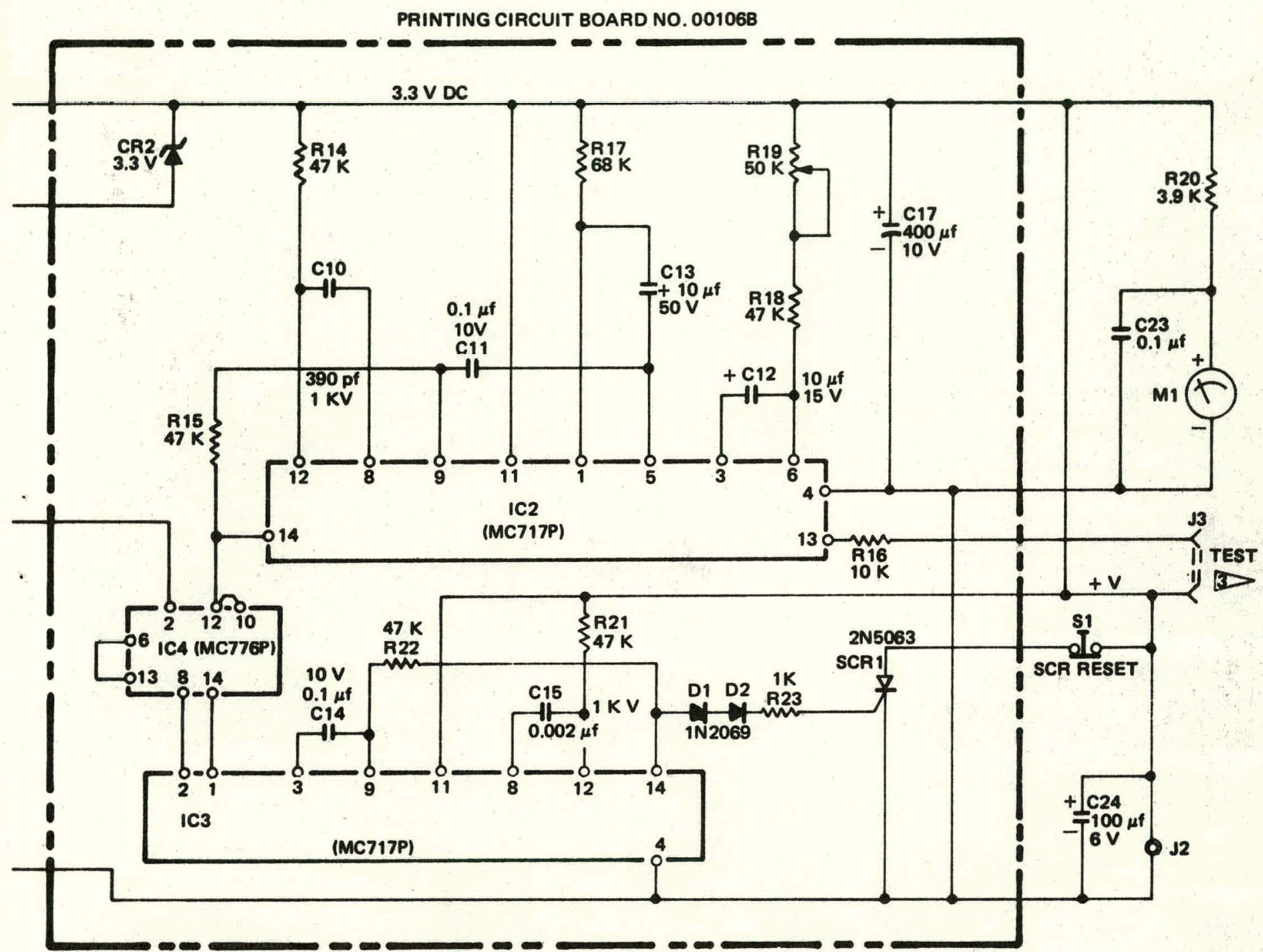

PRINTED CIRUCIT BOARD NO. 00112 DETECTOR ASSEMBLY
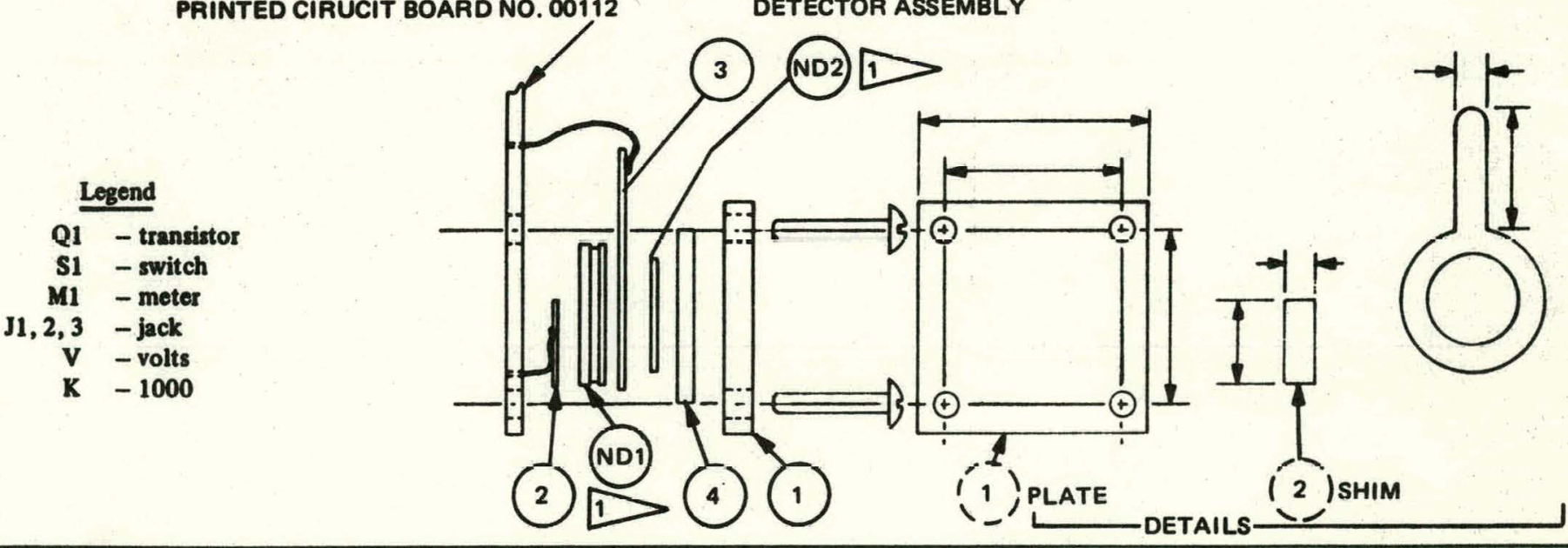


\section{RFP-2027}

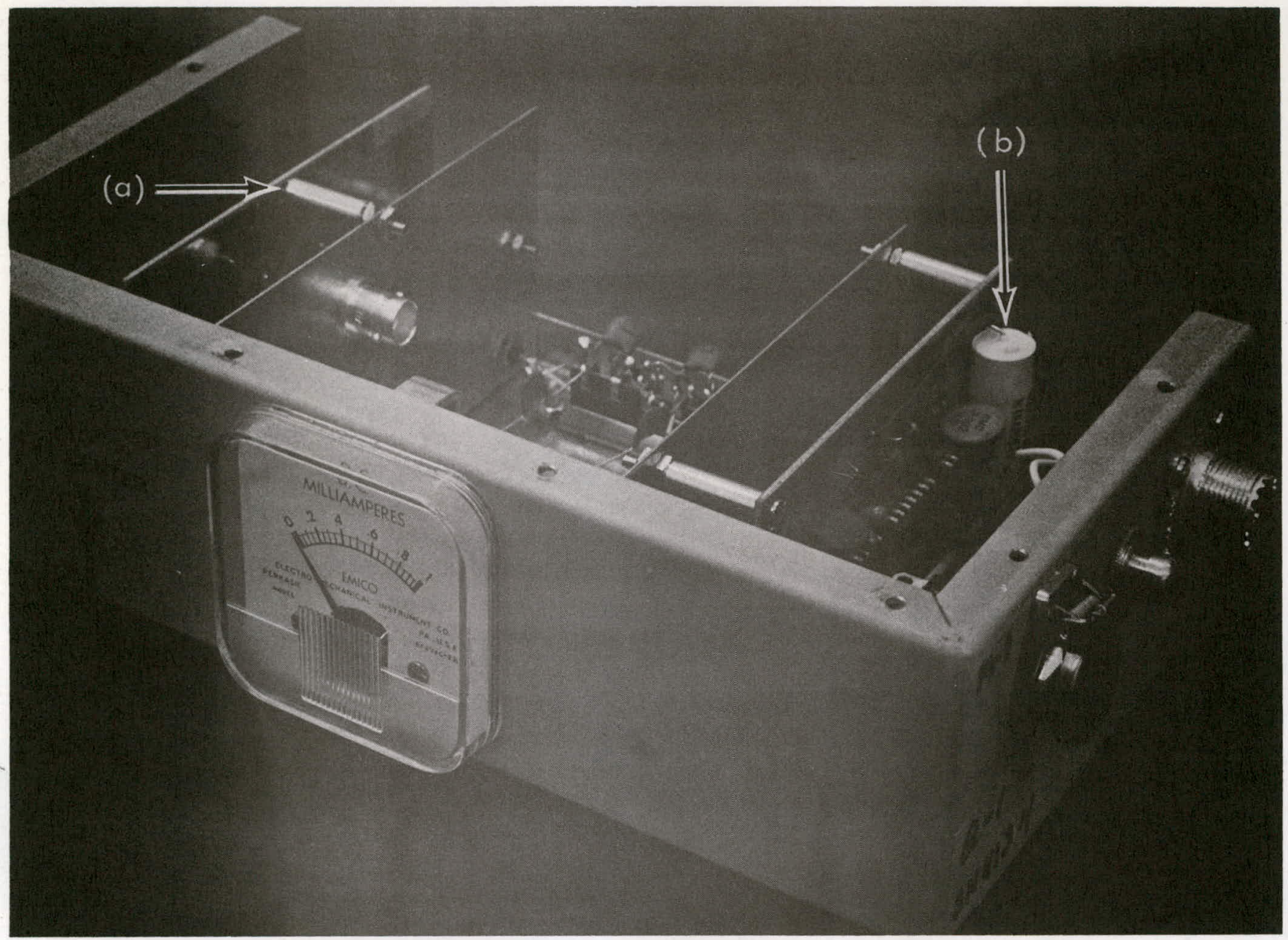

FIGURE 4. Internal Detector Unit Configuration: Board No. 00112 (a) and Board No. 00106B (b).

16439-3

FIGURE 5. Neutron Detection Components: ND1 Detectors (c) and ND2 Foils (d).

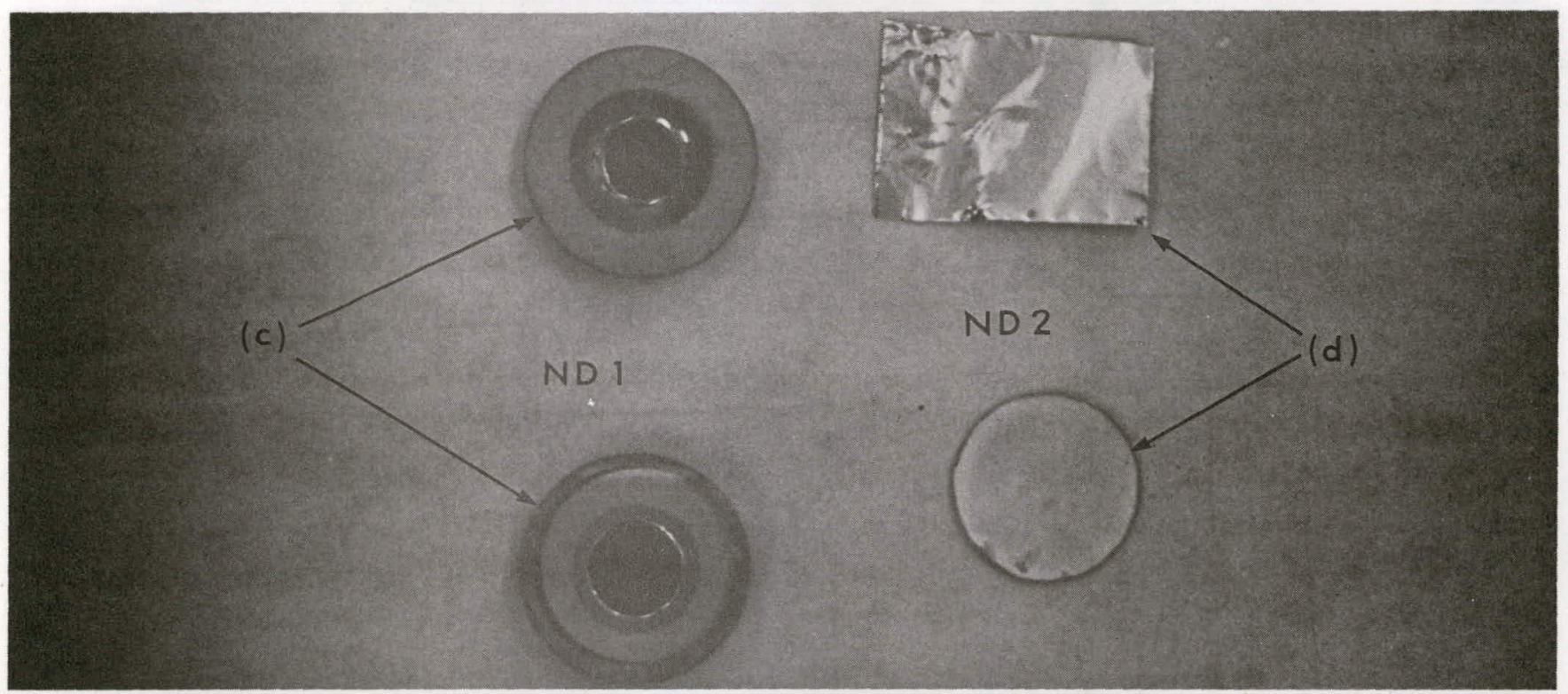




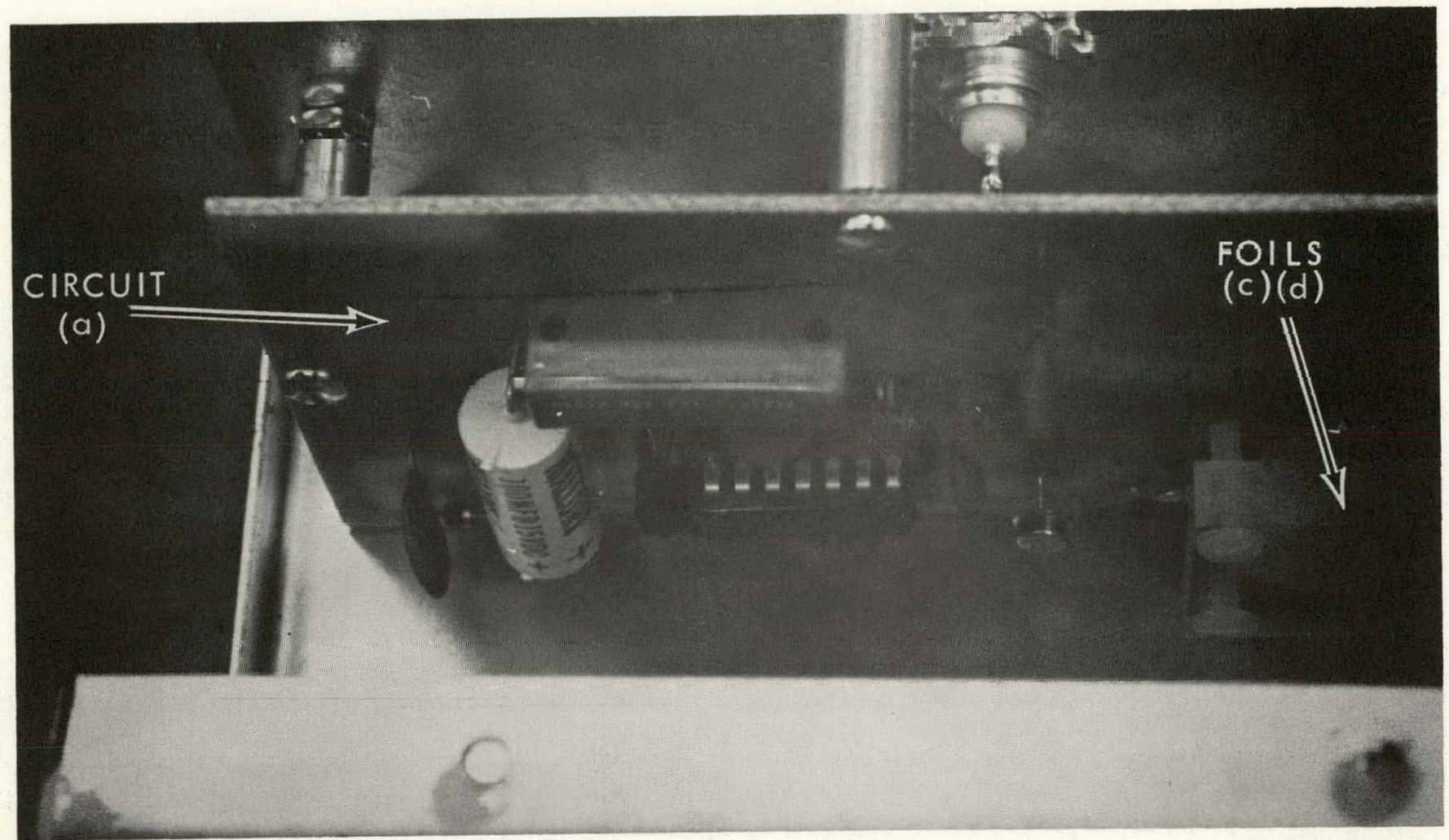

FIGURE 6. Amplifier-Trigger Board No. 00112.

$16439-4$

FIGURE 7. Counter-Sampling Board No. 00106B.

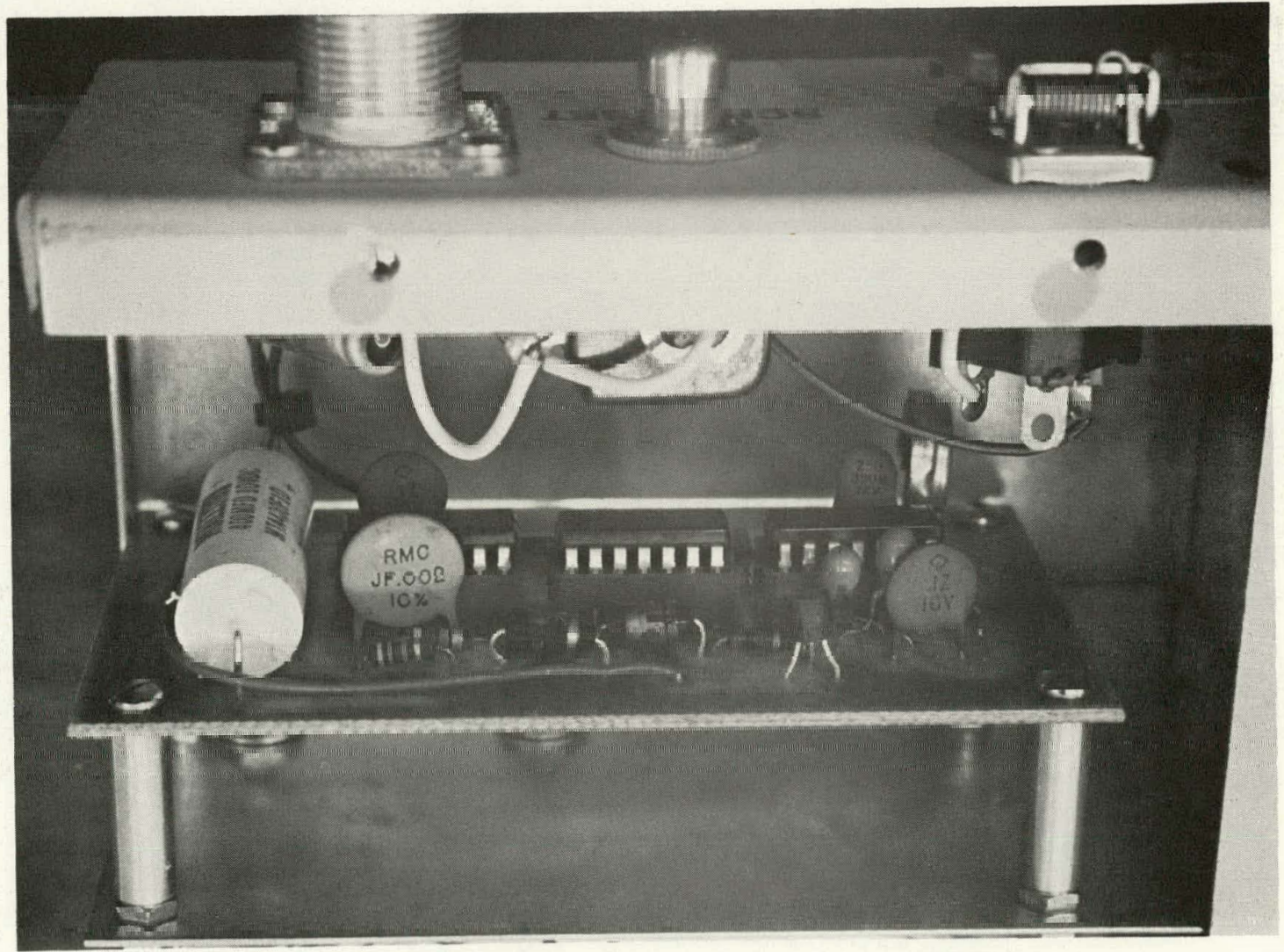




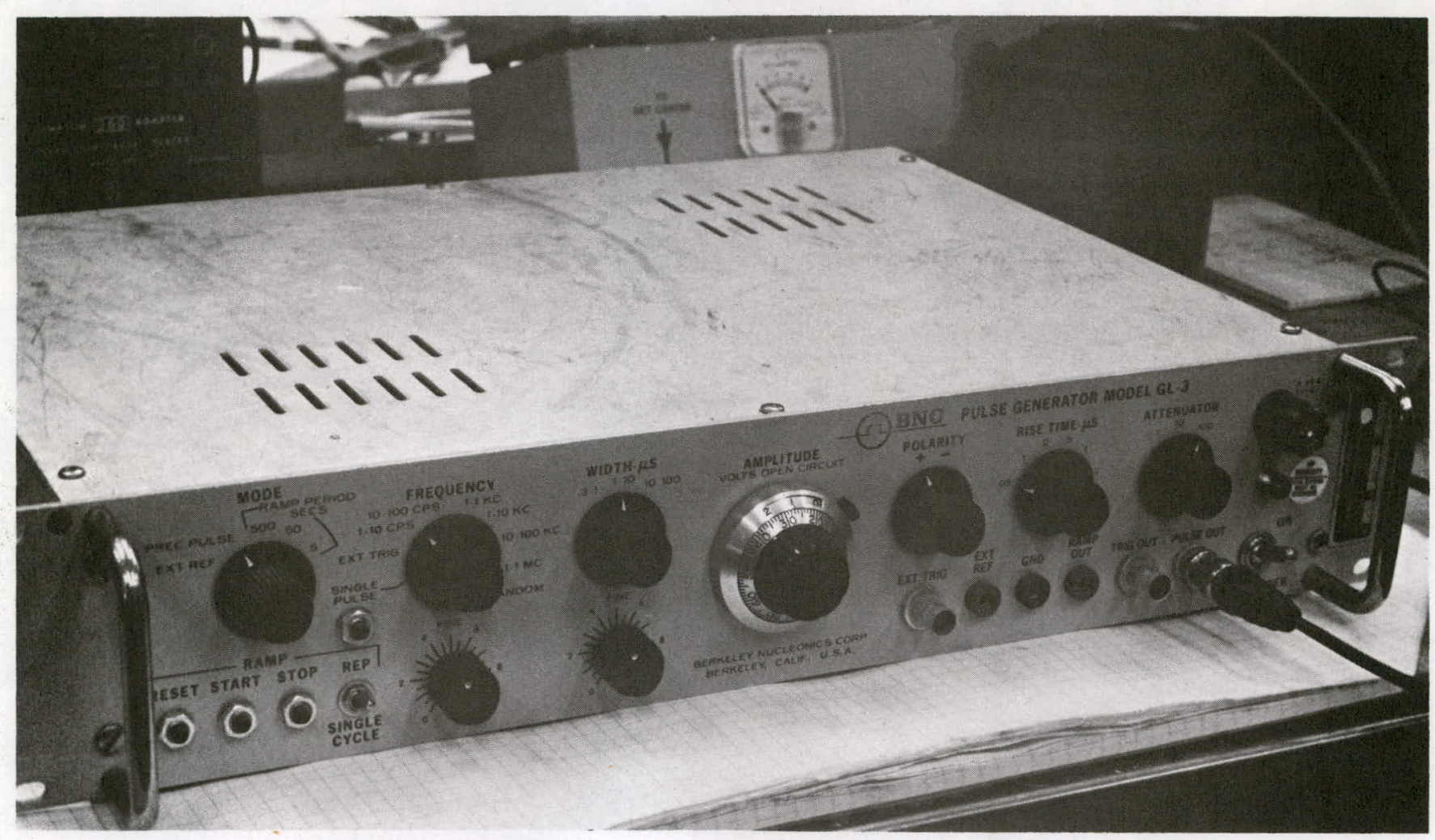

FIGURE 8. Test Pulser (BNC).

$16436-8$ FIGURE 9. Potentiometer (R6) on Amplifier-Trigger Board.

16436-5

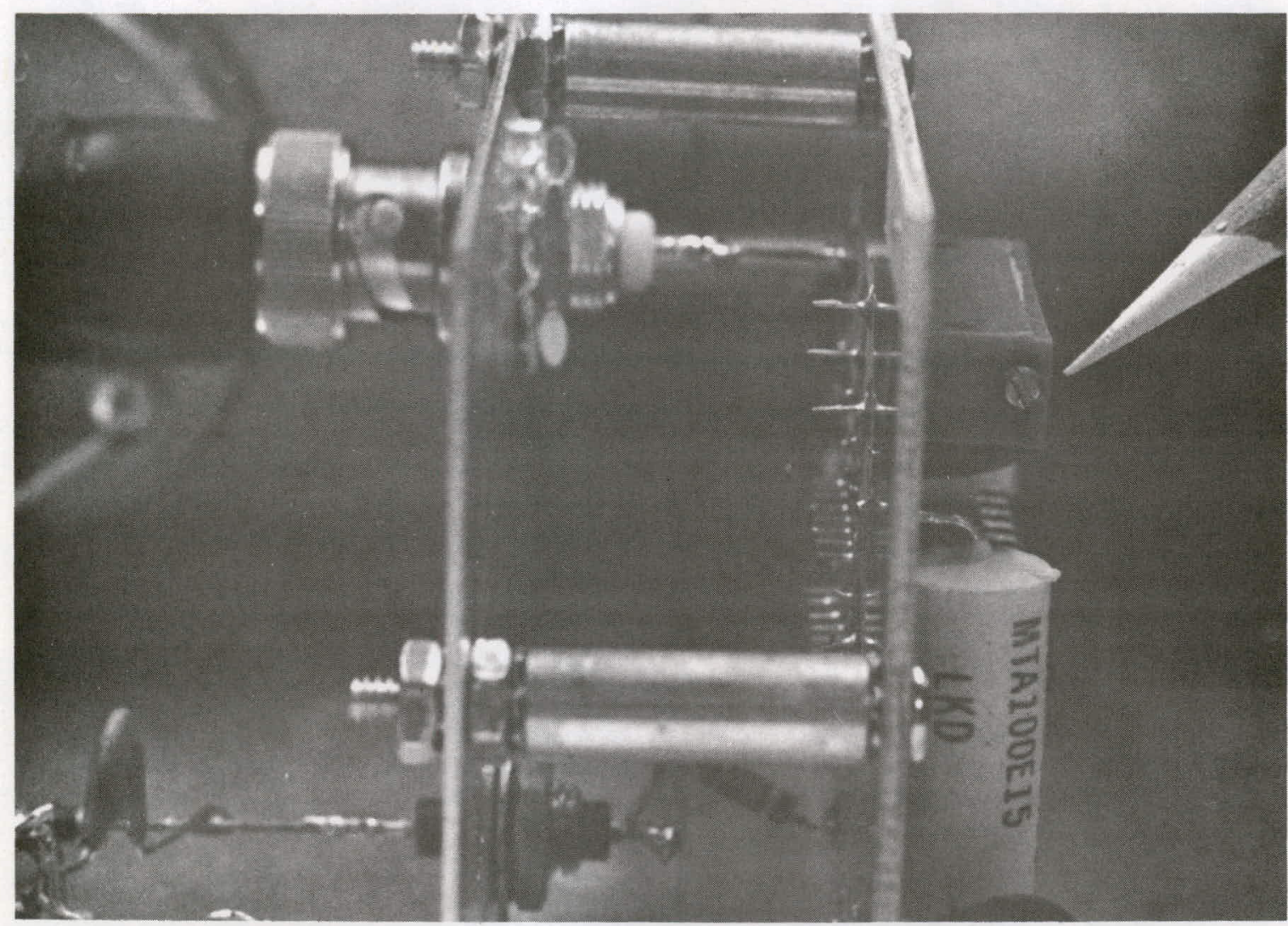


RFP-2027

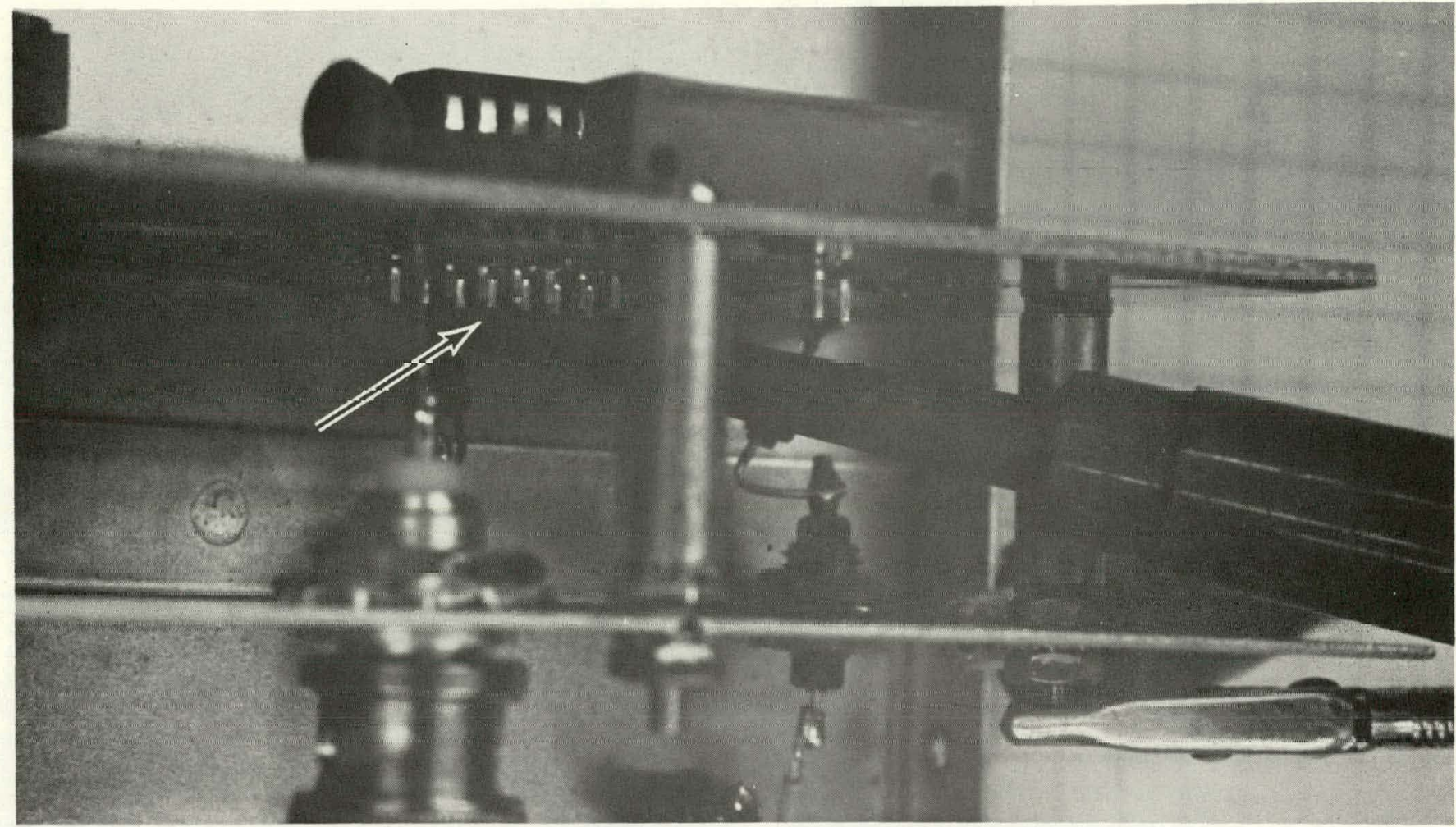

FIGURE 10. Amplifier Trigger Board Output (arrow).

$16436-4$

FIGURE 11. Amplifier Trigger Board Monostable Output.

$16439-10$

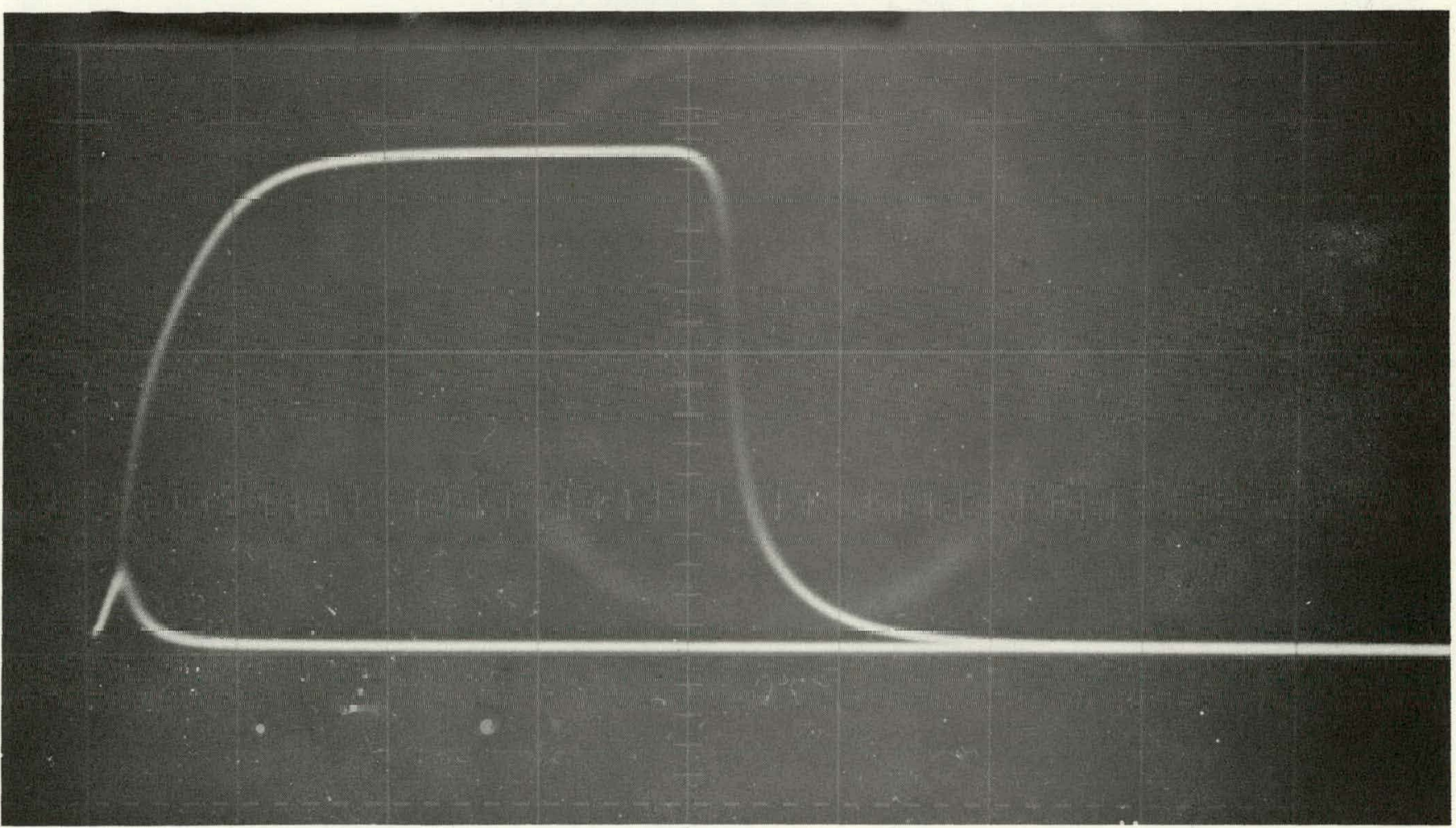


FIGURE 12. Reset Sampling Generator Timing.
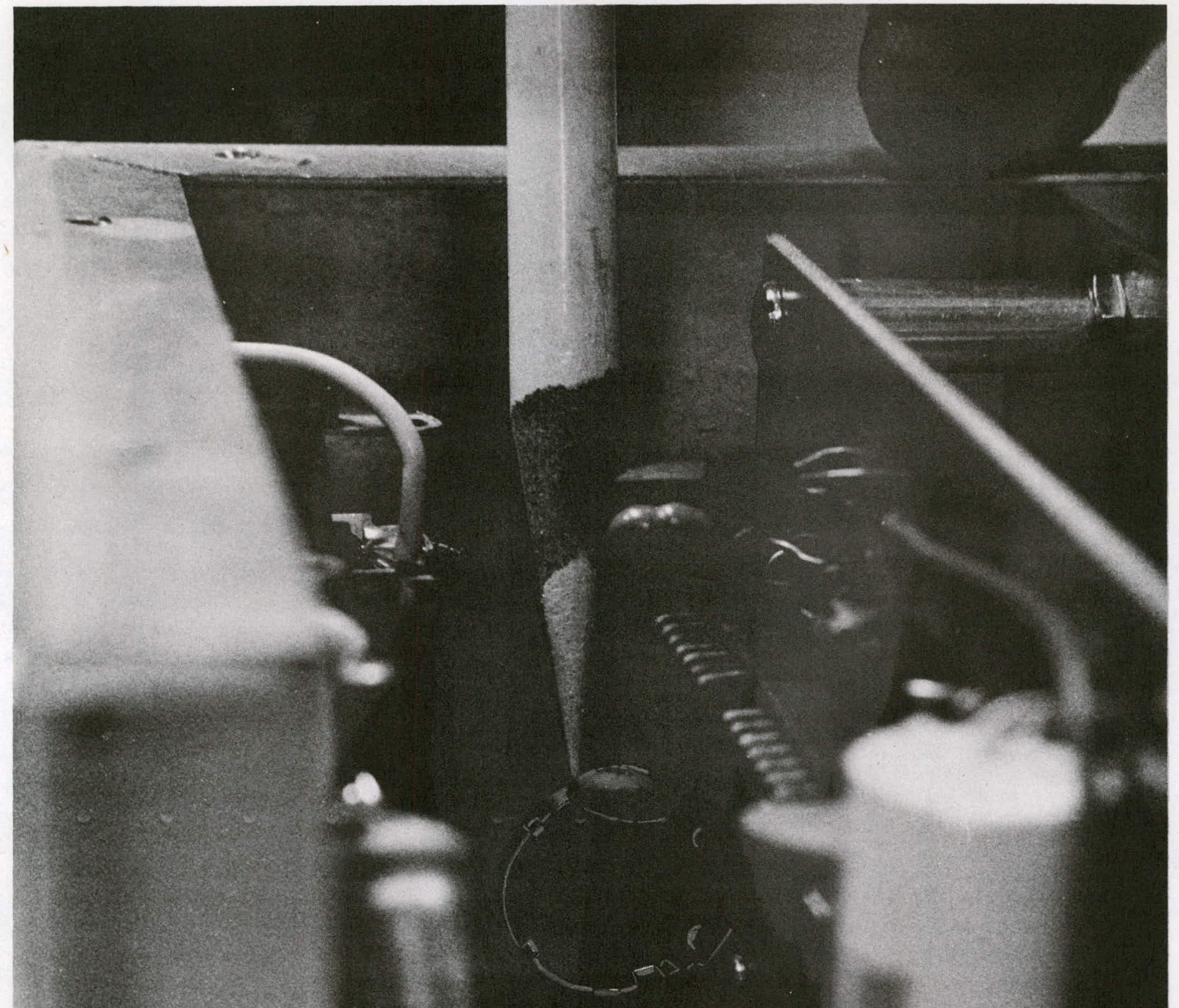


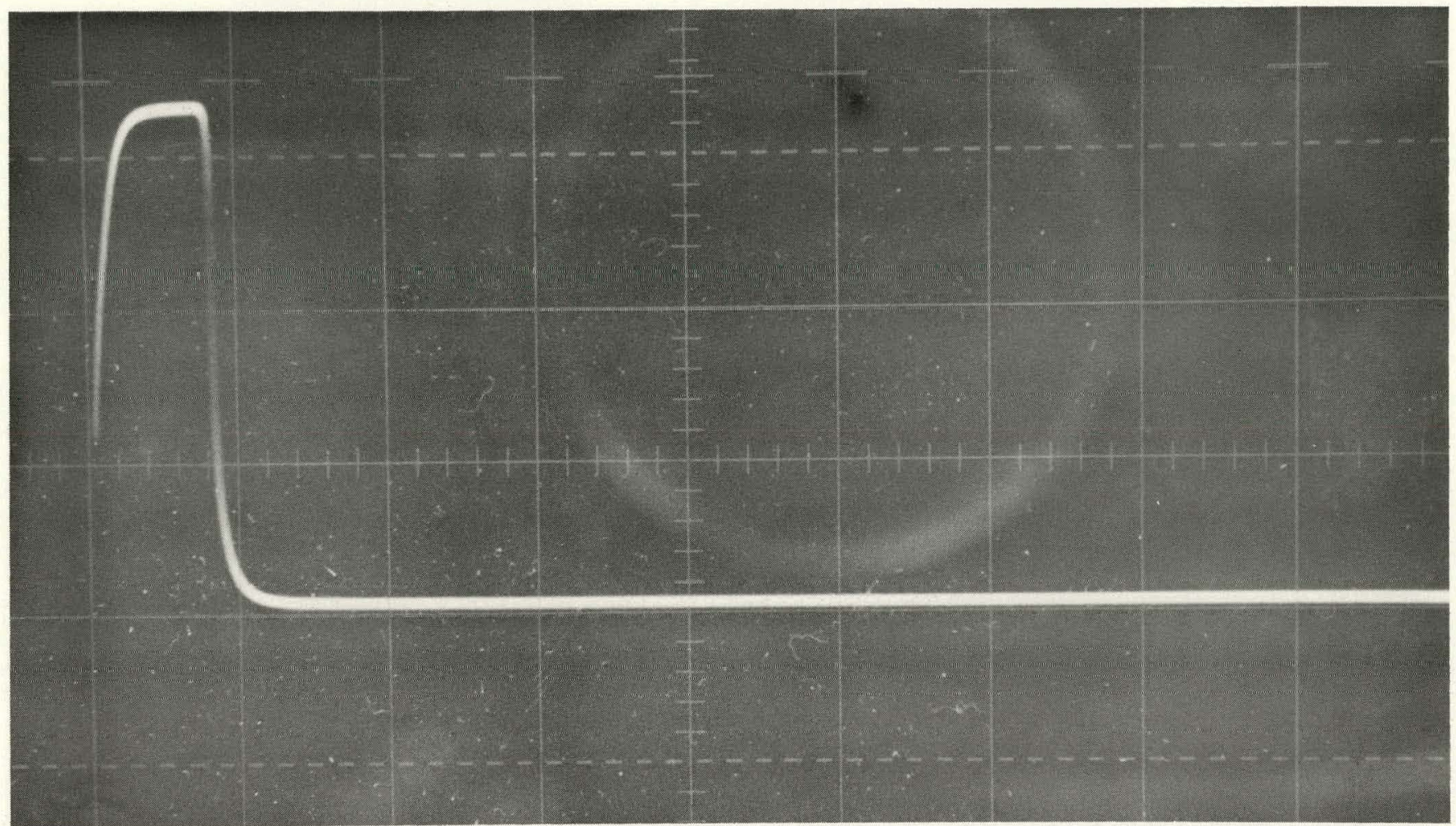

FIGURE 13. Sample Generator Monostable Output.

16439-9

FIGURE 14. Inserted Test Plug for Detector Unit.

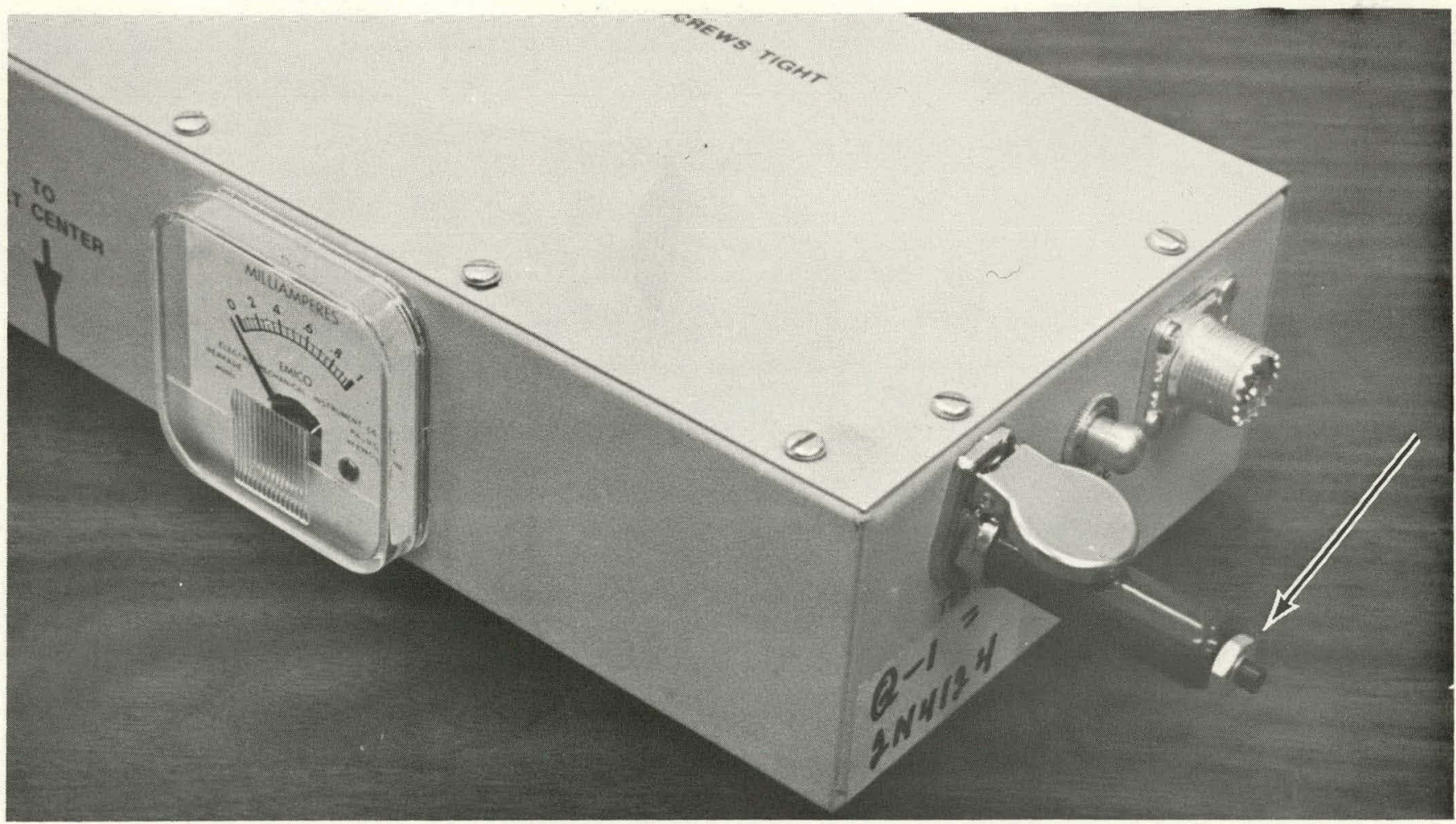




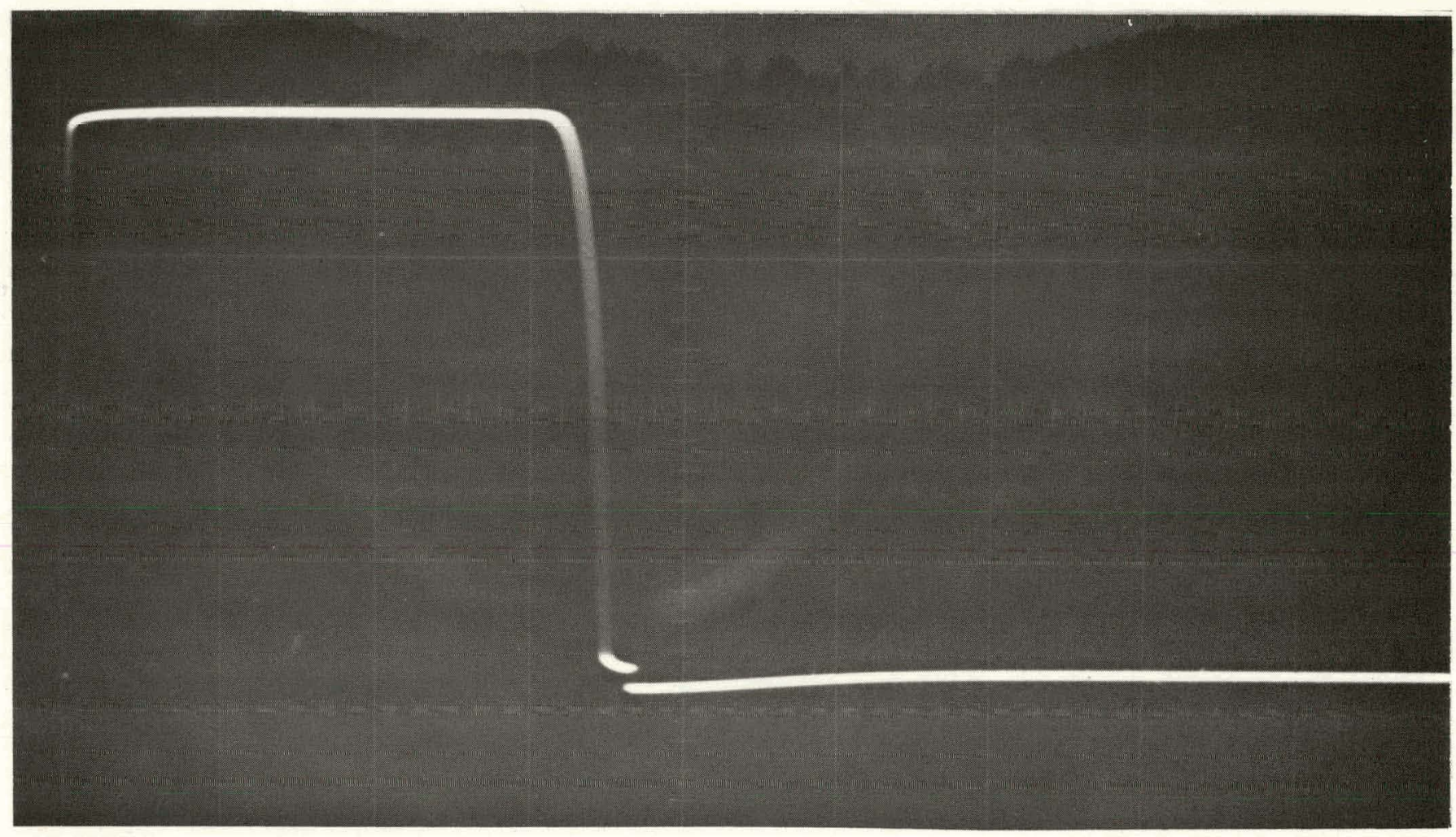

FIGURE 15. Silicon Controlled Rectifier (SCR) Monostable Output Pulse.

$16436-2$

FIGURE 16. Detector Unit with Neutron Test Source.

$16437-1$

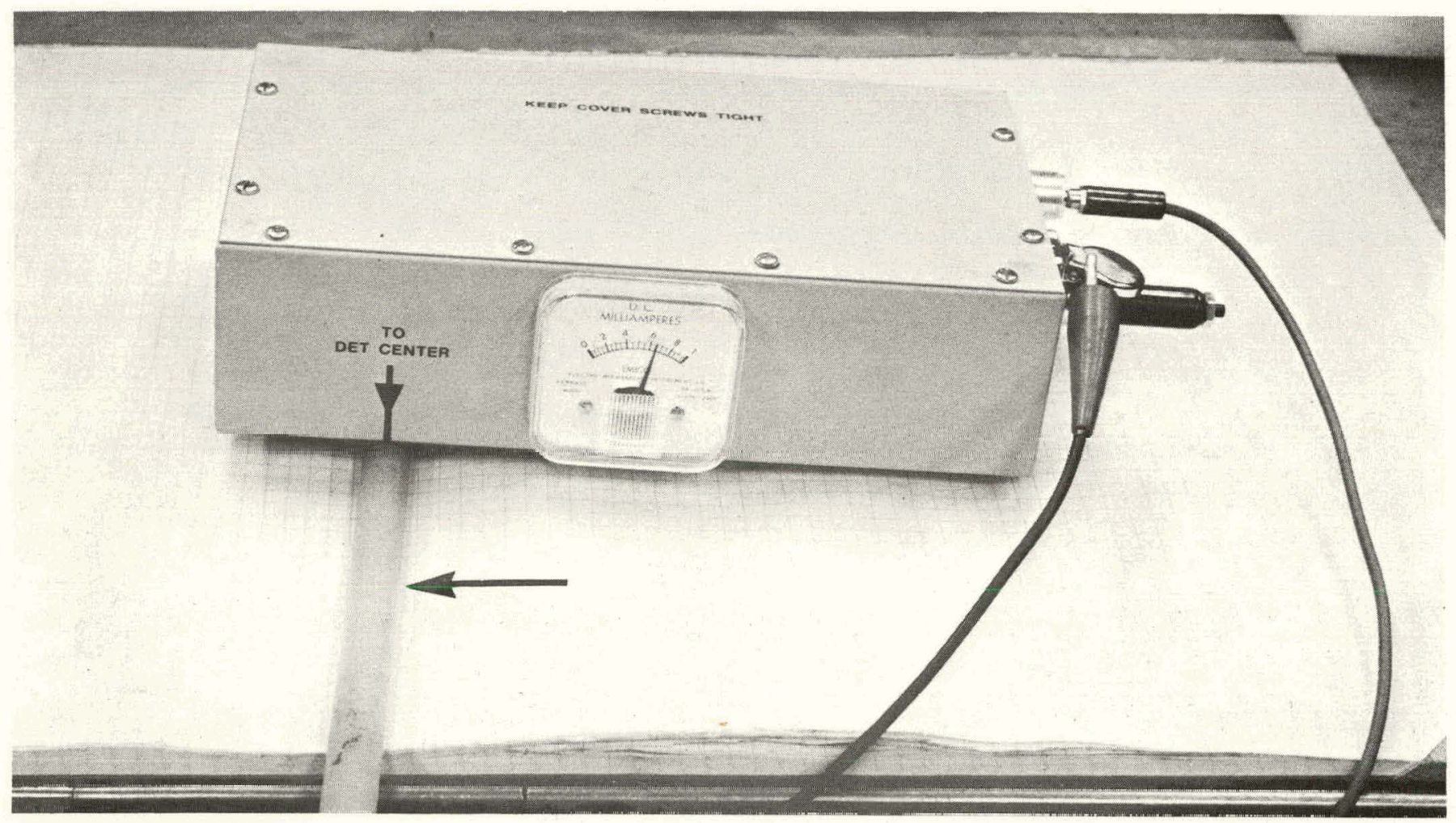


FIGURE 17. Main Display Terminal Block Diagram.

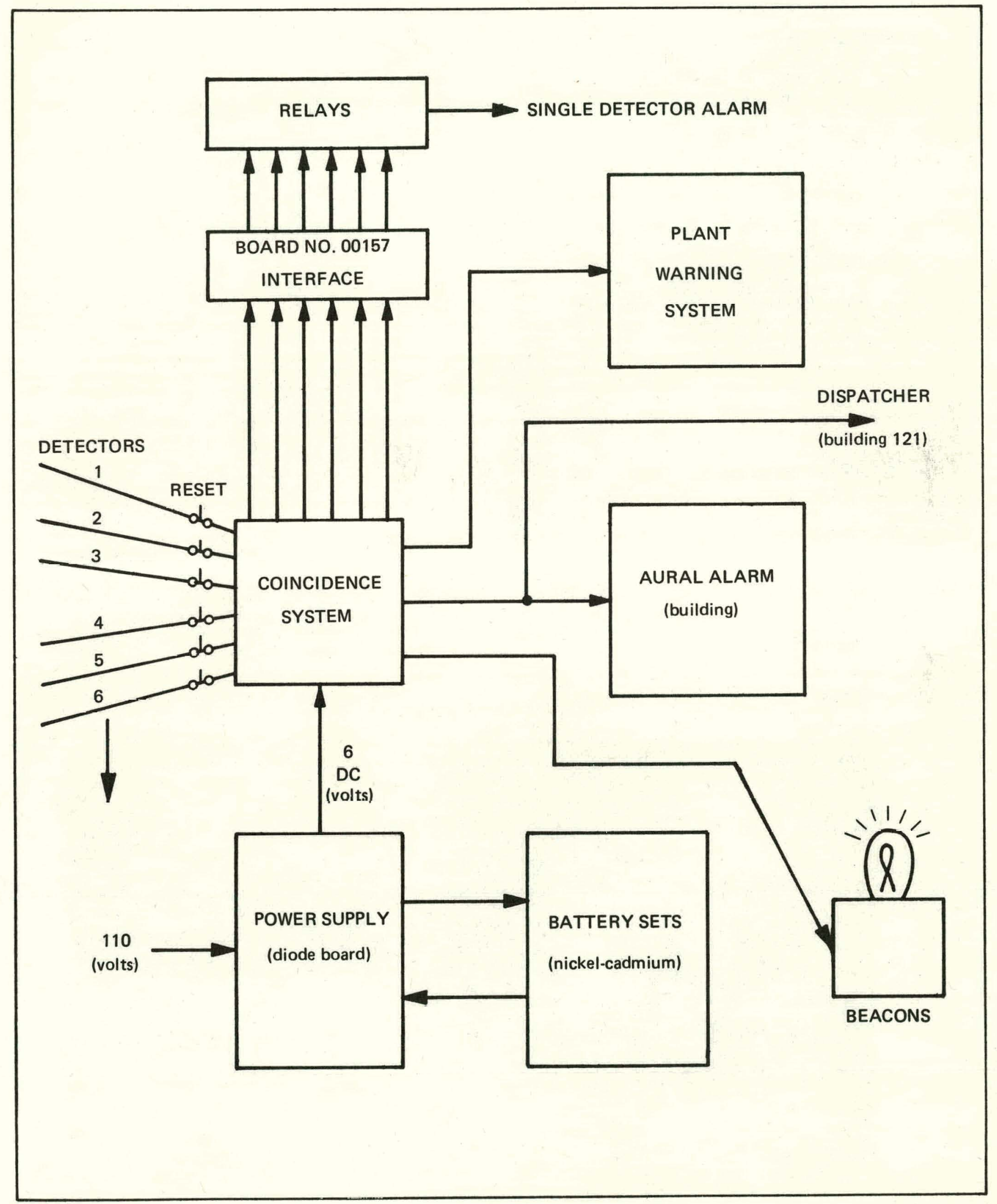




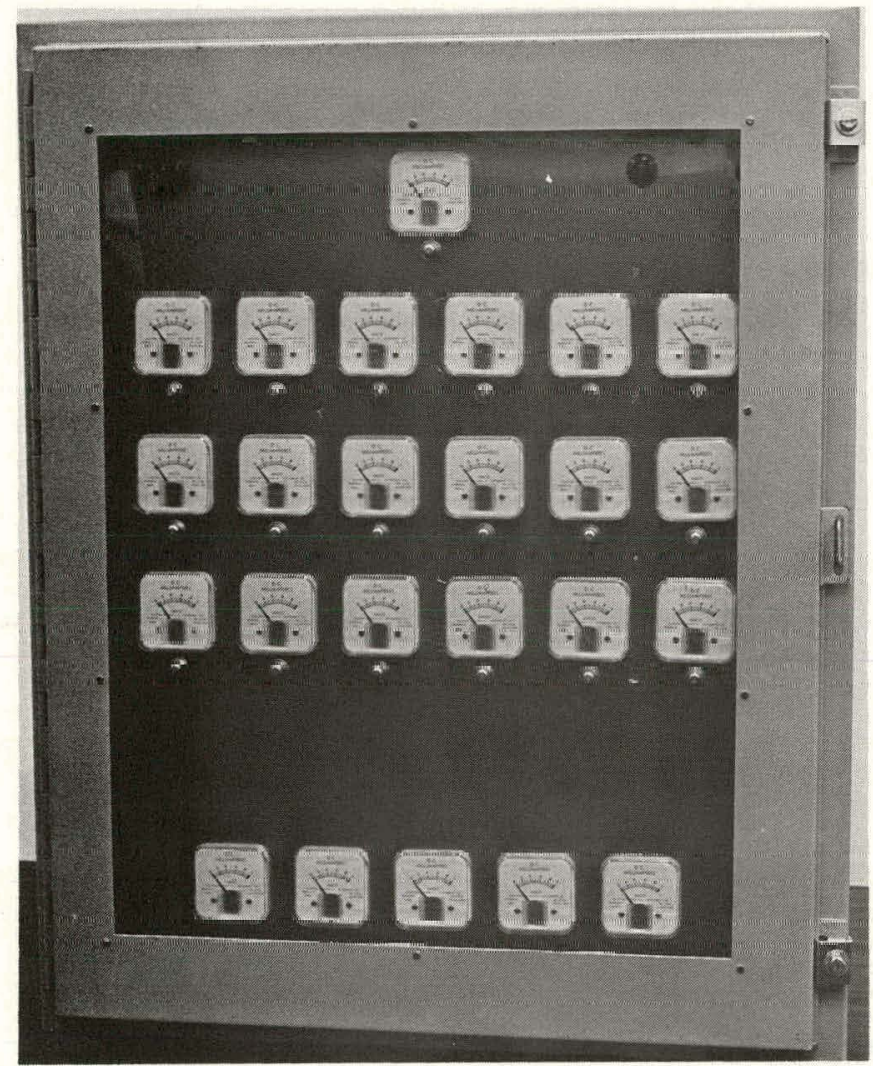

16568-11

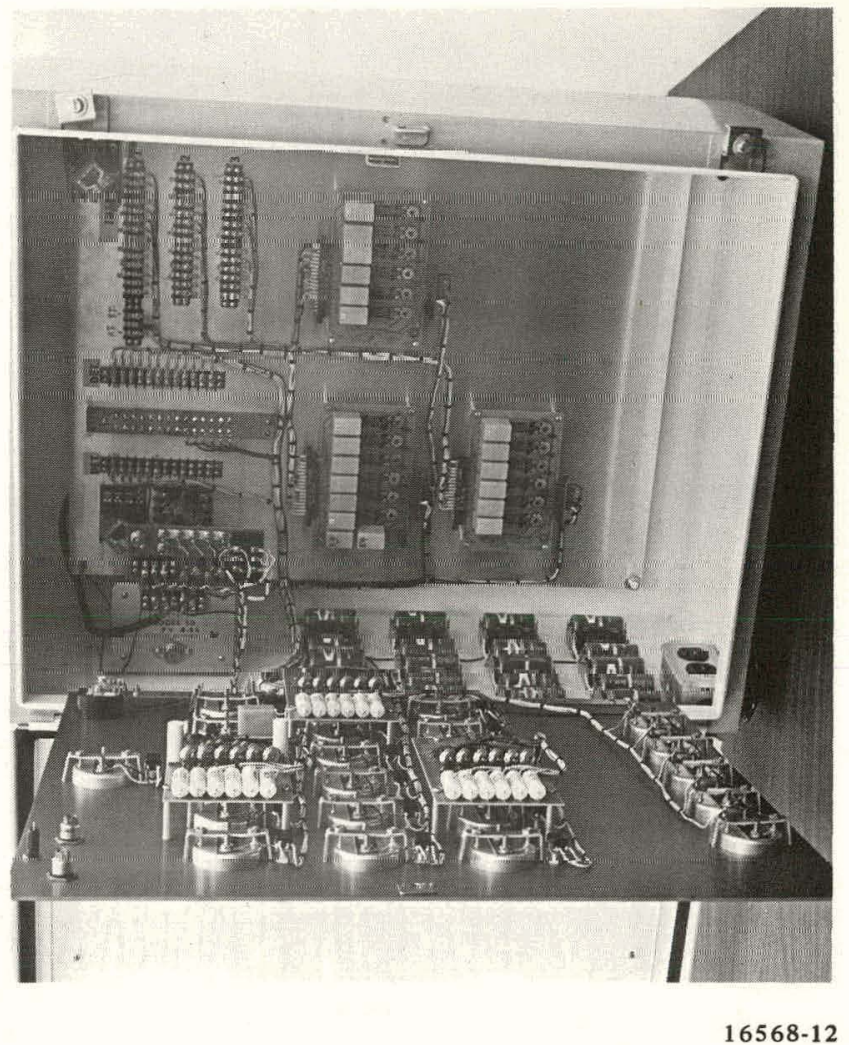

FIGURE 19. Interior of Main Display Terminal.

FIGURE 18. External View of Main Display Terminal.

FICURE 20. Main Display Terminal Test Set.

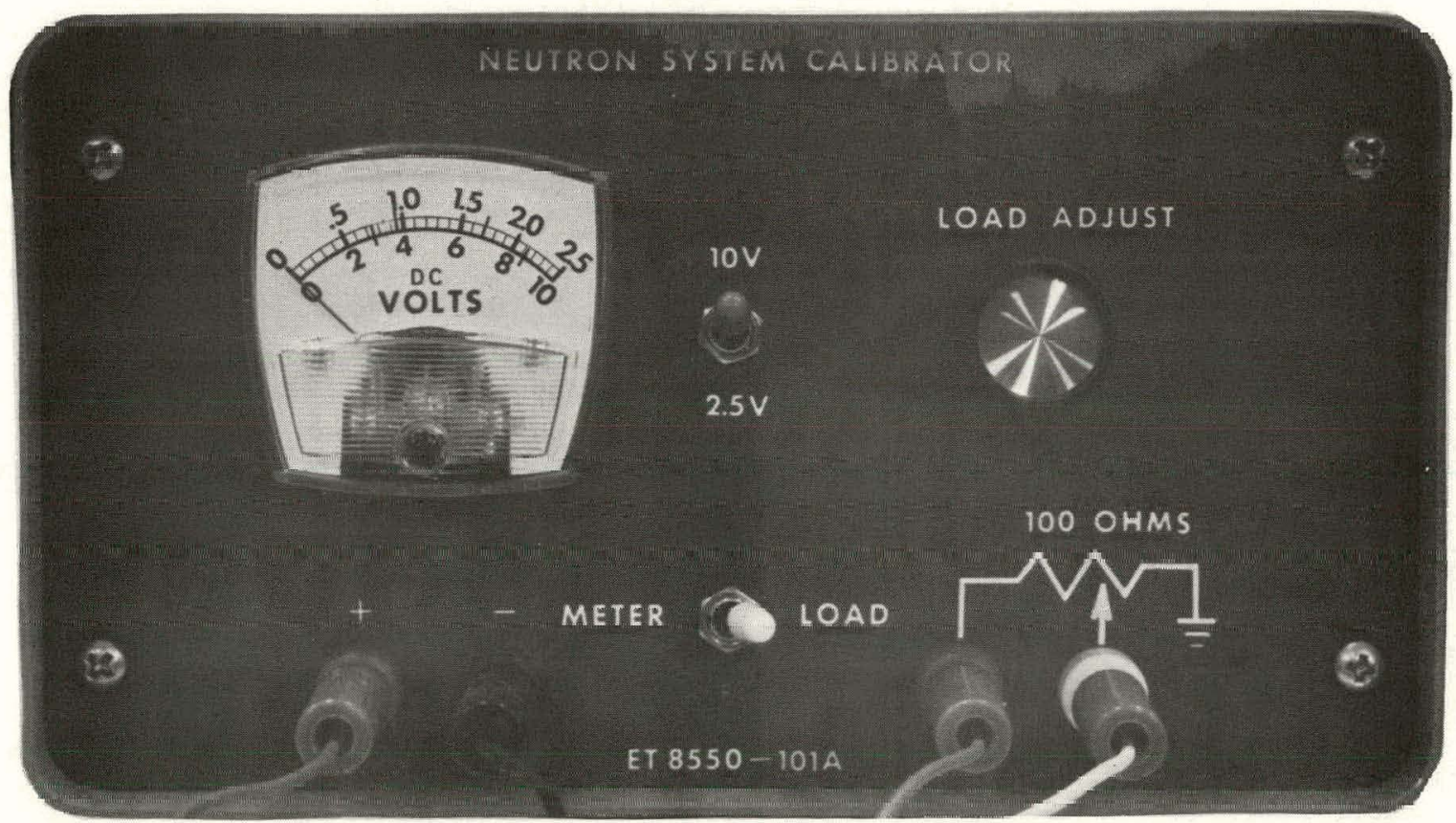


FIGURE 21. Test Set Front Panel Dimensions (inches).

FIGURE 22. Test Set Circuit.

\section{Legend}
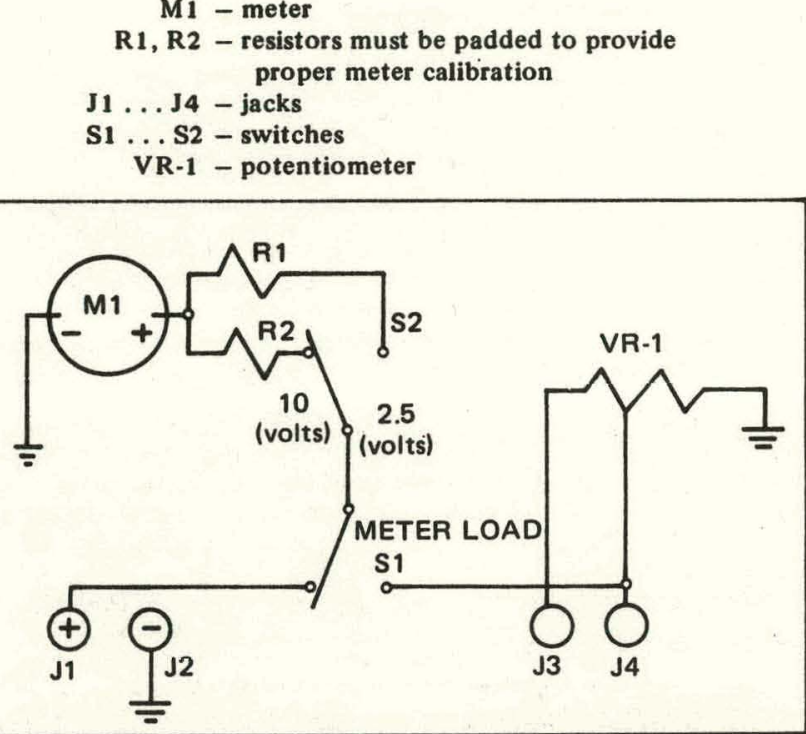

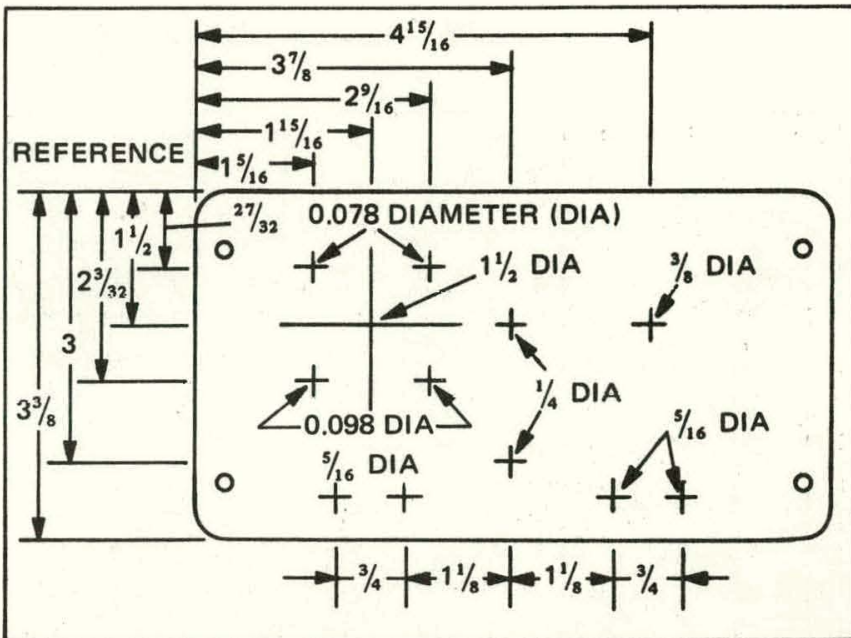

FIGURE 23. Test Set Parts List.

Meter - M1, 50 Movement, Radio Shack No. 22-017

Switch - S1 and S2, SPDT Toggle Switch, Alco No. 105D

Potentiometer - VR-1, 100 ohms, A-B No. CJPIN05561014 Jack - J1 and J3, Banana Jack, E. F. Johnson No. 108-902, red

Jack - J2, Banana Jack, E. F. Johnson No. 108-903, black

Jack - J4, Banana Jack, E. F. Johnson No. 108-907, Yellow

Resistor - R1, 51,000 ohms, 0.25 watts, 5 percent

Resistor - R2, 200,000 ohms, 0.25 watts, 5 percent

Cabinet - Zero No. ZIC-407

FIGURES 24 and 25. Substitute System Test Parts: 15-ohm resistors and 100-ohm potentiometers.
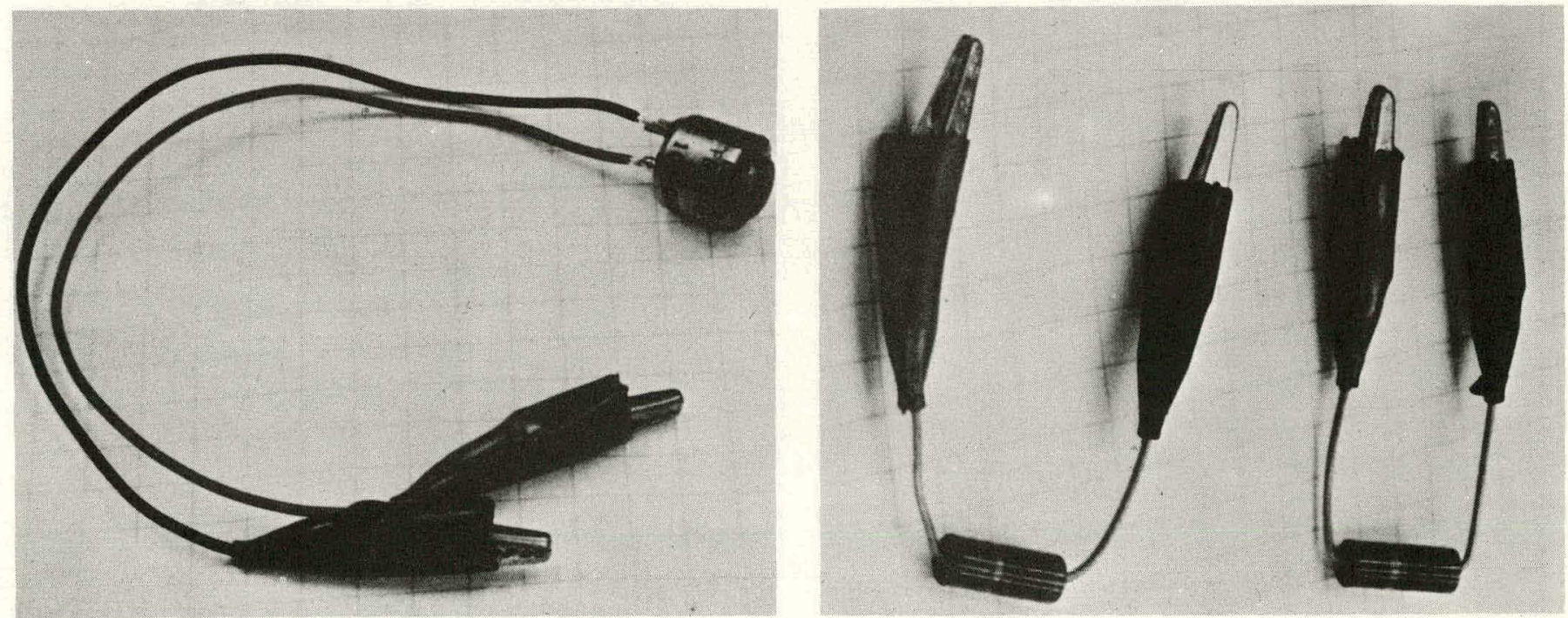
FIGURE 26. Main Display Terminal Schematic for Six-Detector Input.

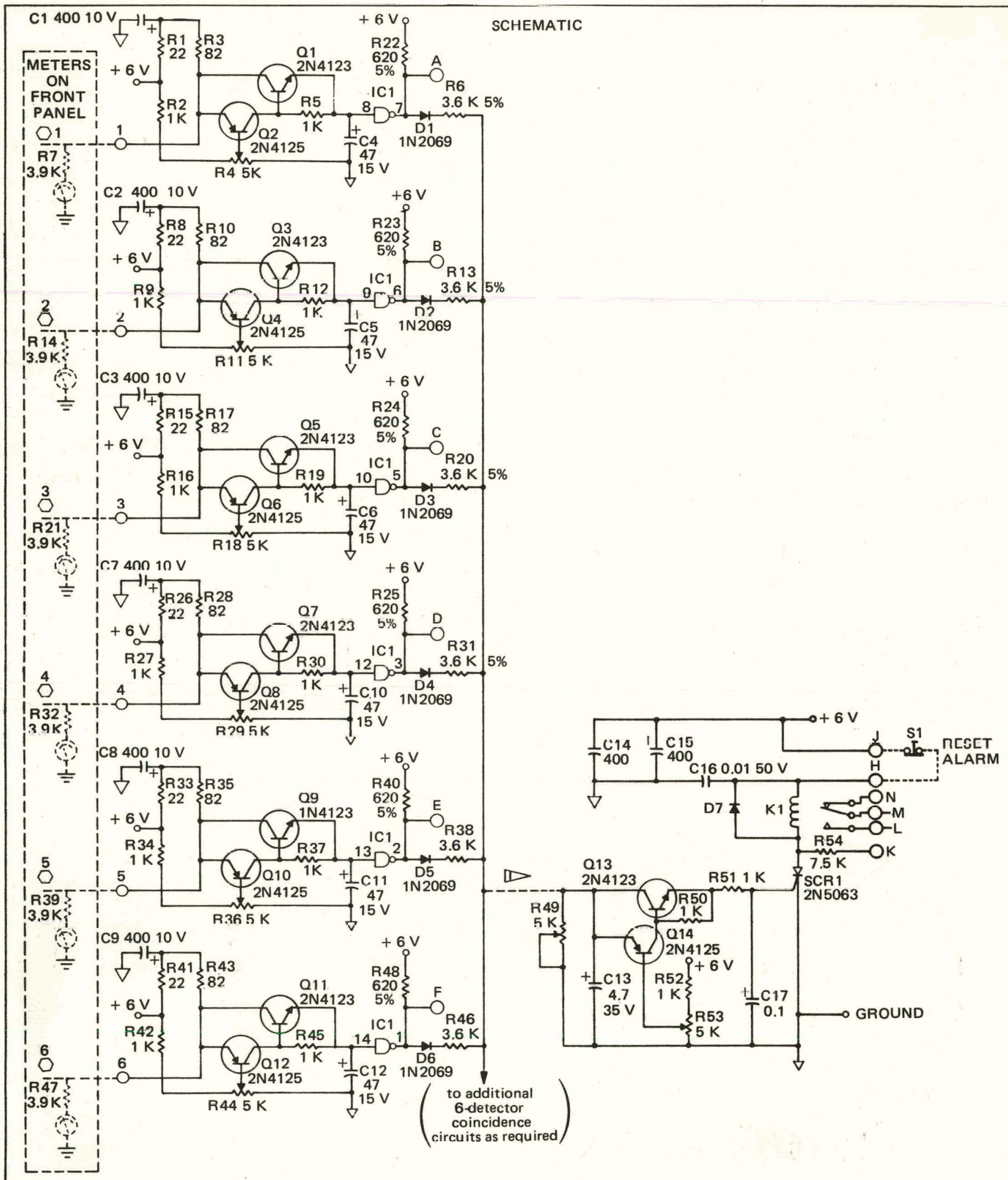


FIGURE 26. (continued).

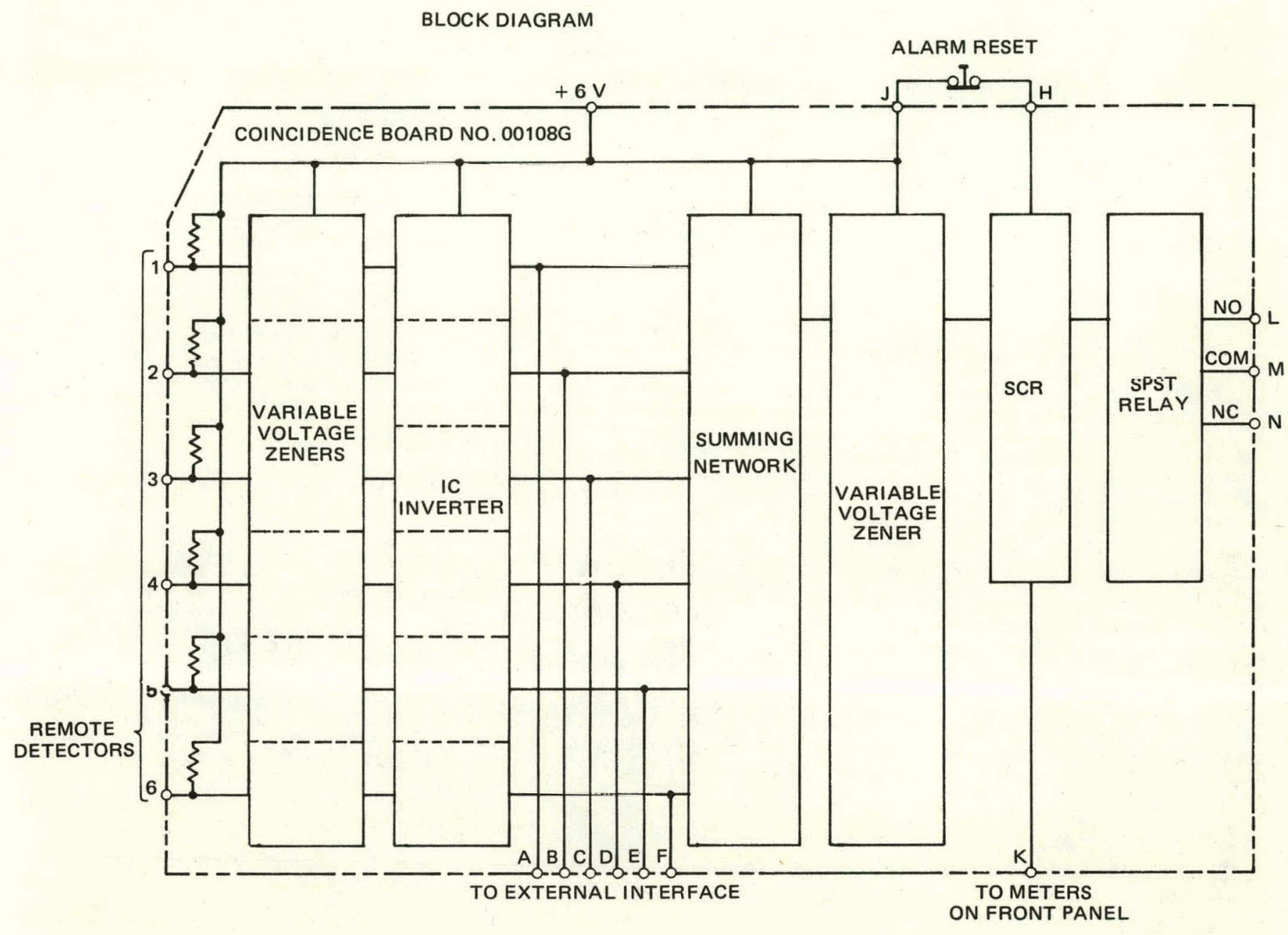

$\underline{\text { Legend }}$
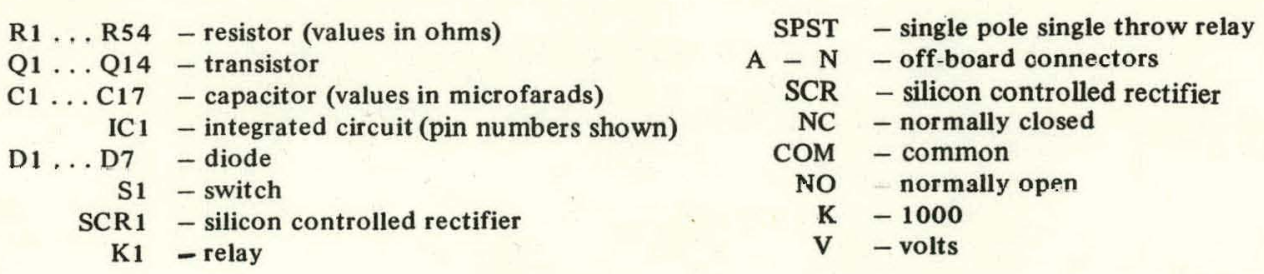

(resistance tolerances noted are \pm 5 percent) 
FIGURE 27. Upper Interior of Terminal with Test Set.

$16438-1$

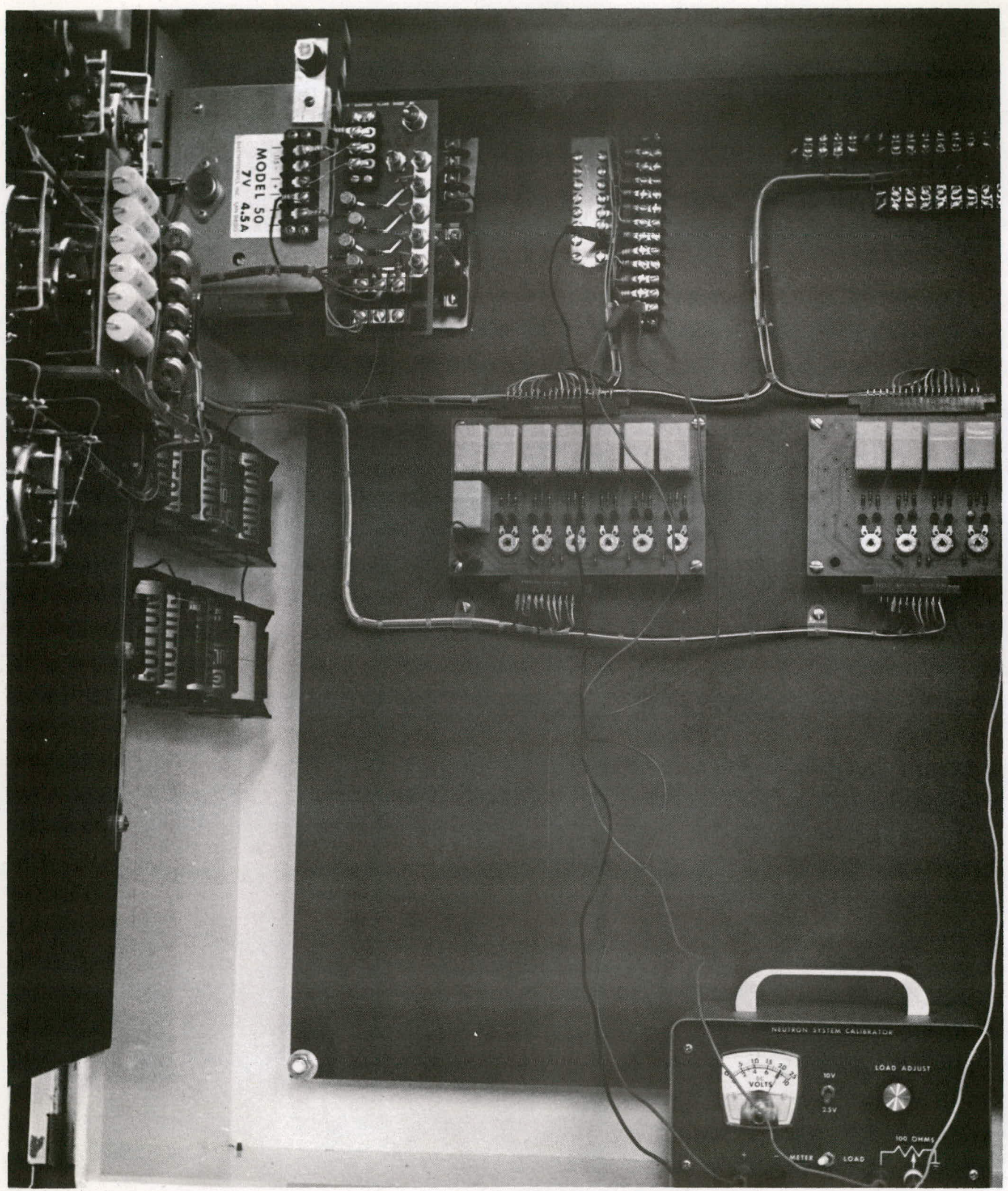




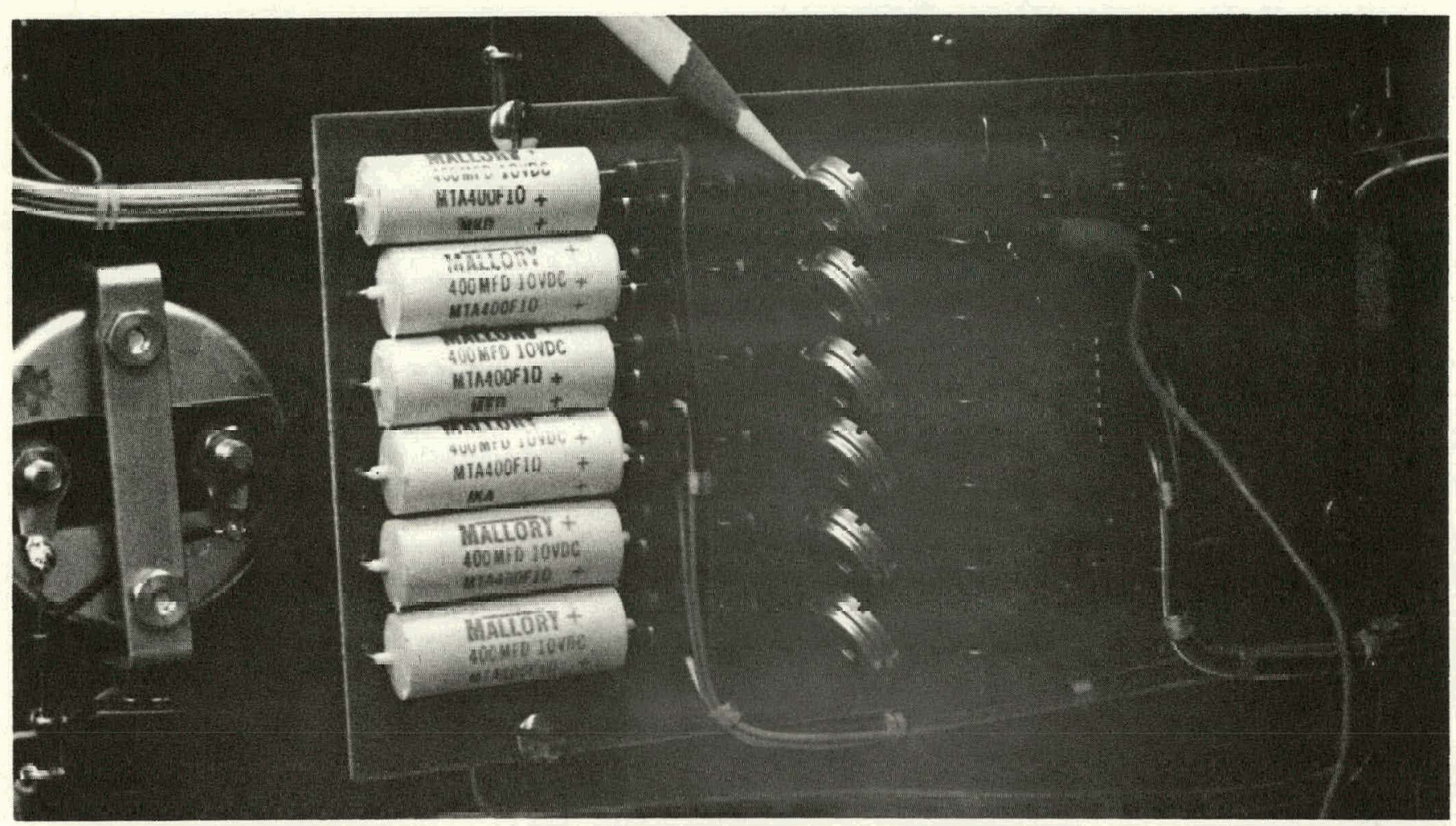

FIGURE 28. Coincidence Board Input Trigger Circuit Potentiometers.

$16438-5$

FIGURE 29. Voltage Measurement at OR Gate Diode.

16438-6

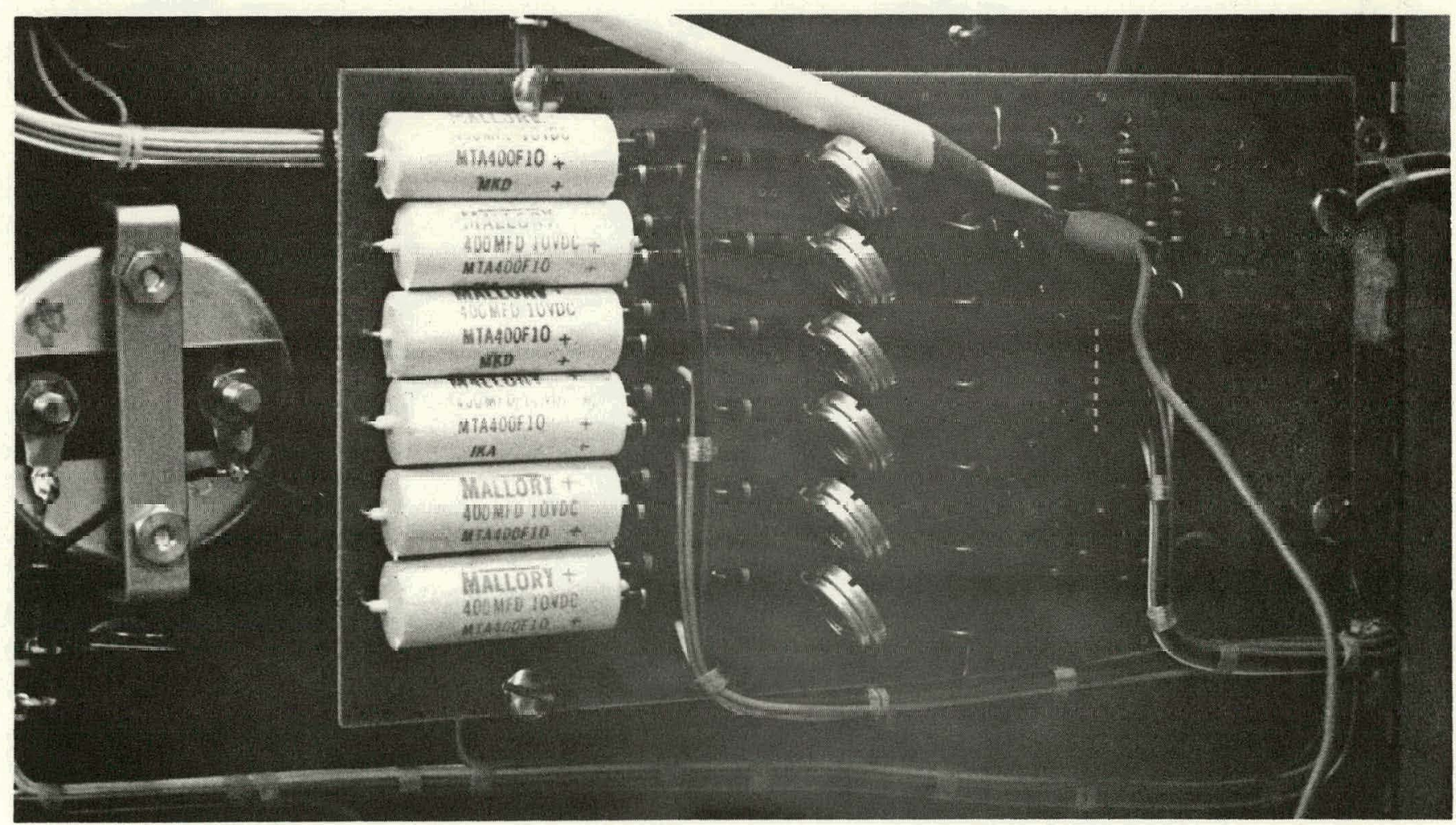




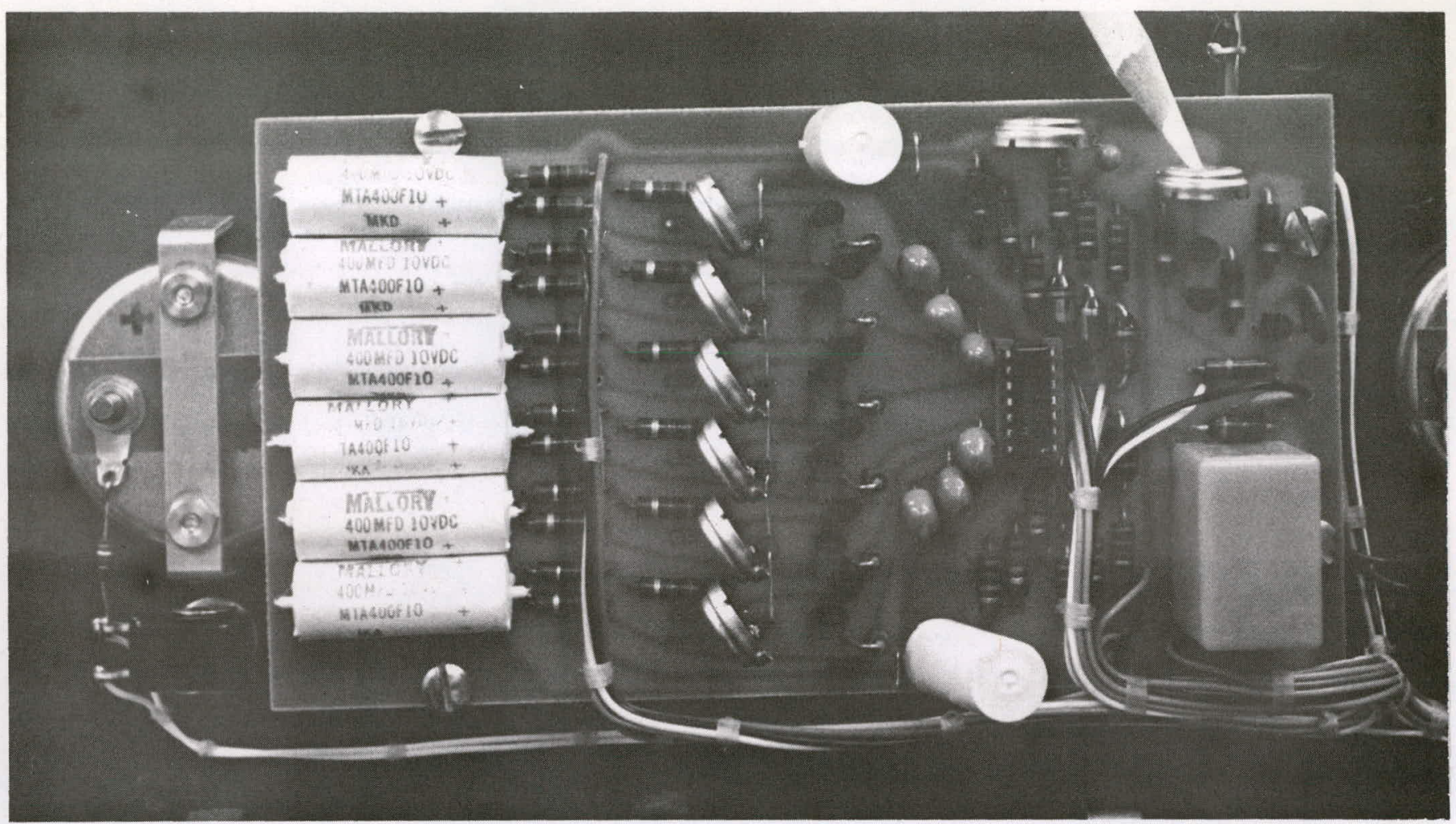

FIGURE 30. Trigger Circuit (R53) of Coincidence Board.

16438-7

FIGURE 31. Potentiometer (R49) of Coincidence Board.

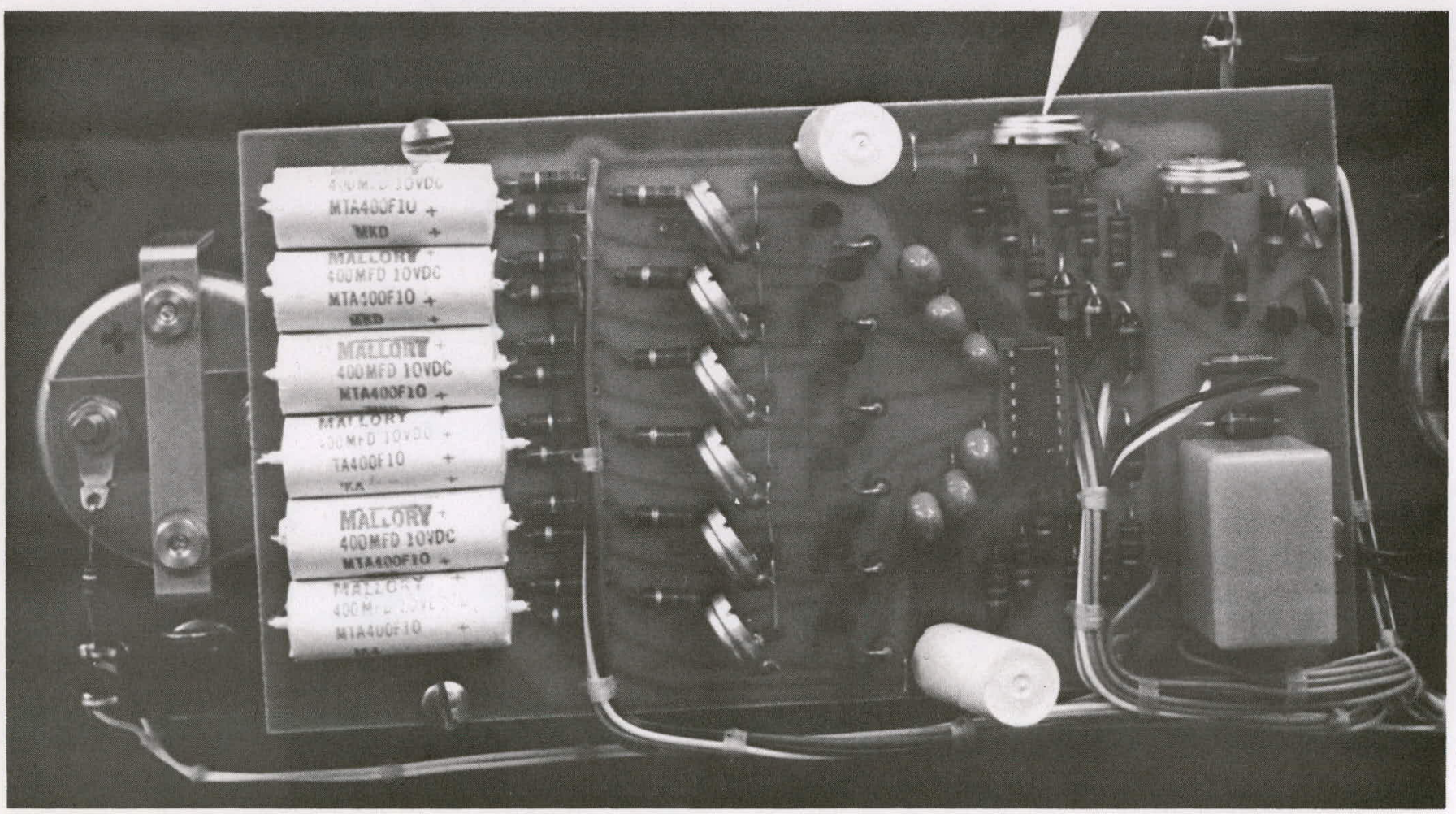


FIGURE 32. Interface Board Schematic.

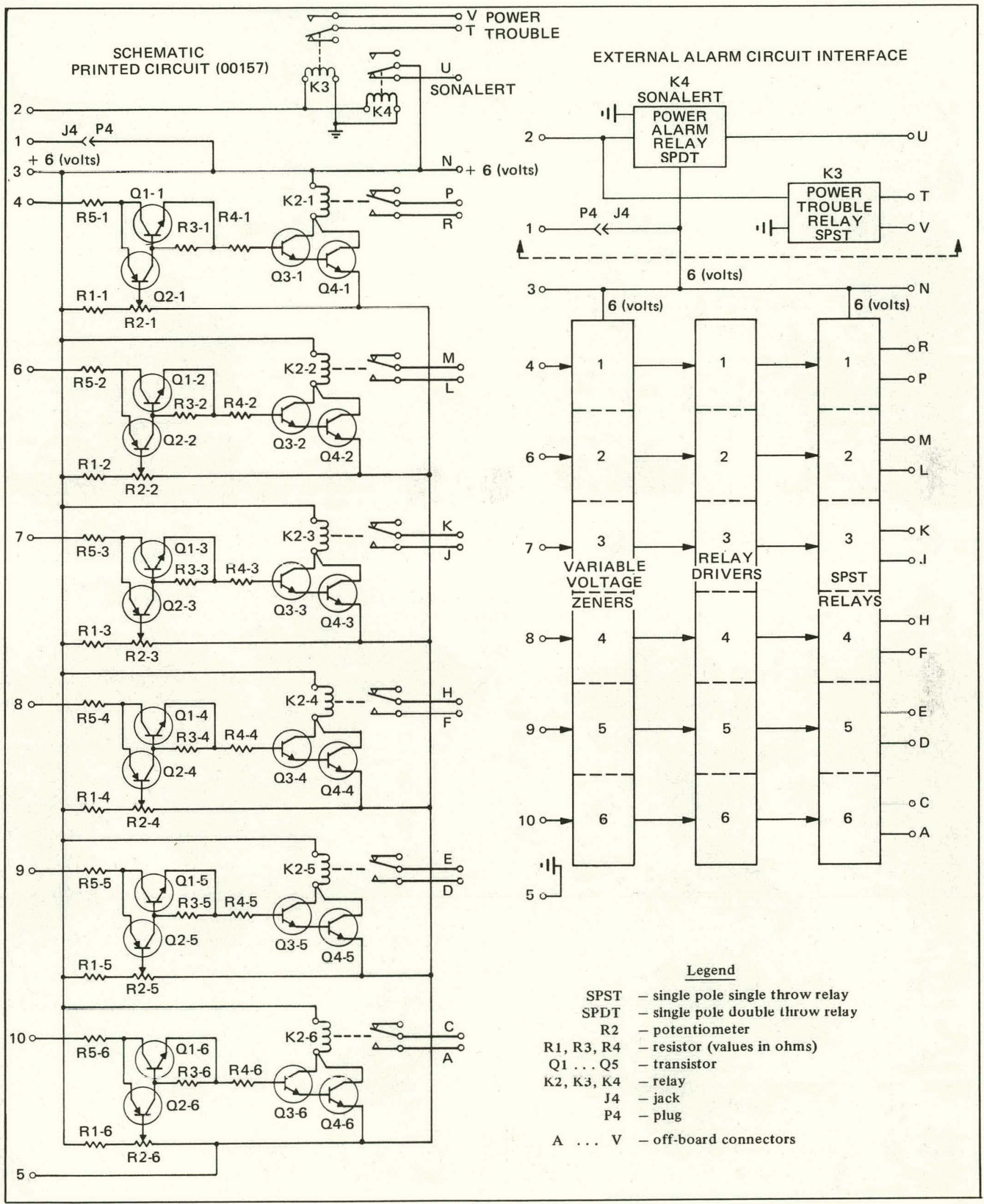


RFP-2027

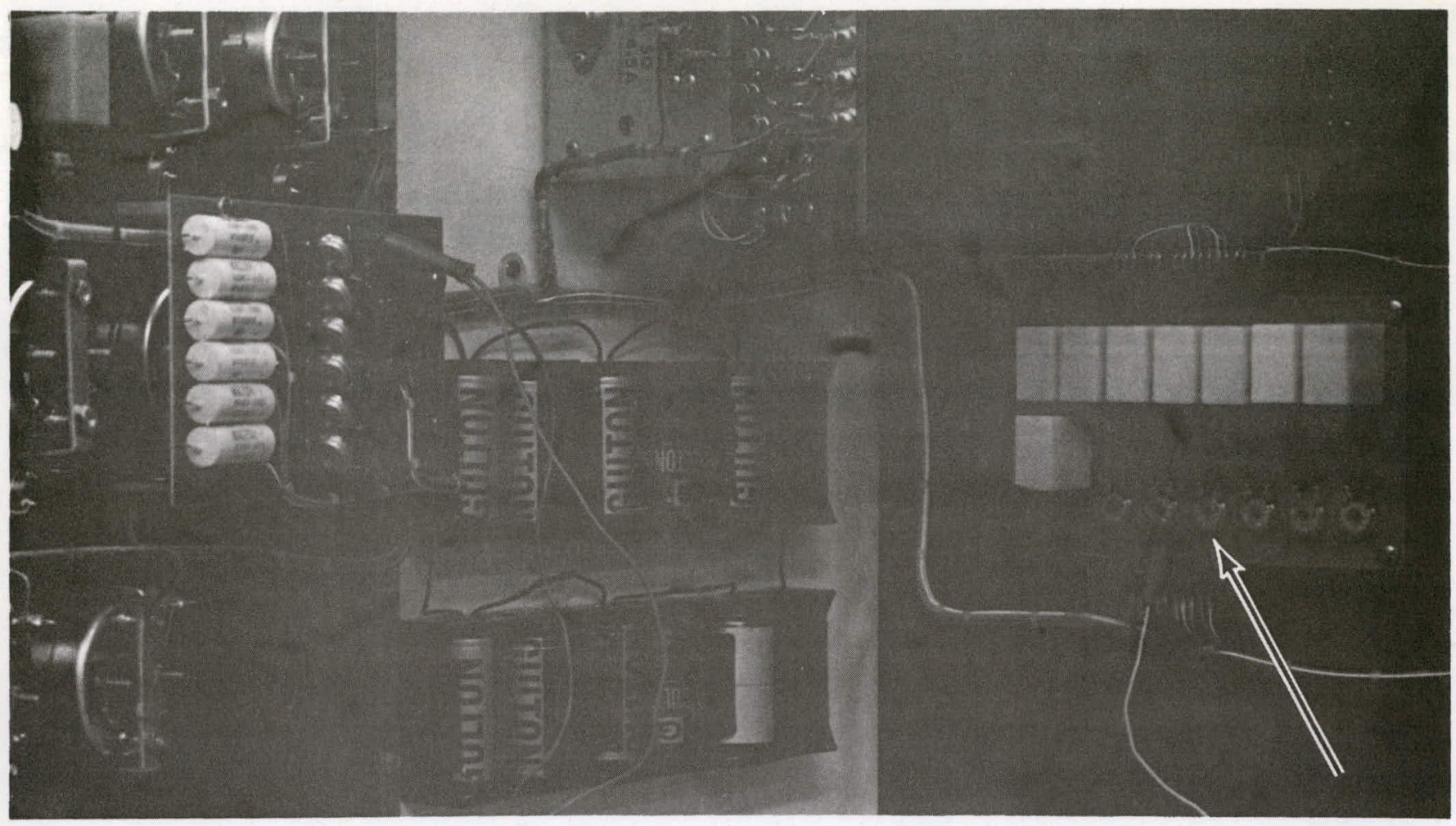

FIGURE 33. Interior of Main Display Terminal with Test Set Input to Interface Board.

$16438-9$

FIGURE 34. Input Potentiometers for Interface Board.

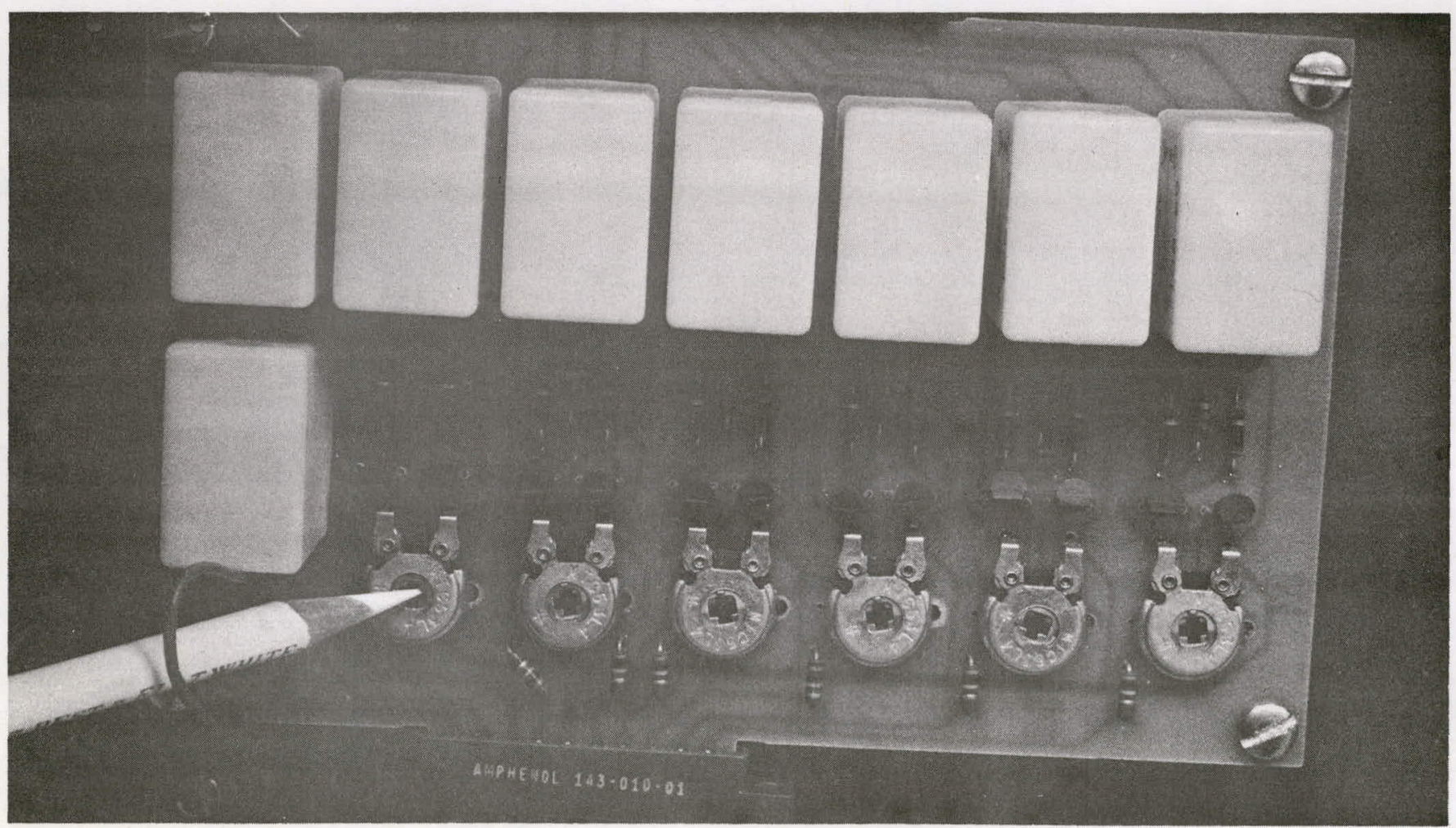


FIGURE 35. Signal Generator Schematic.

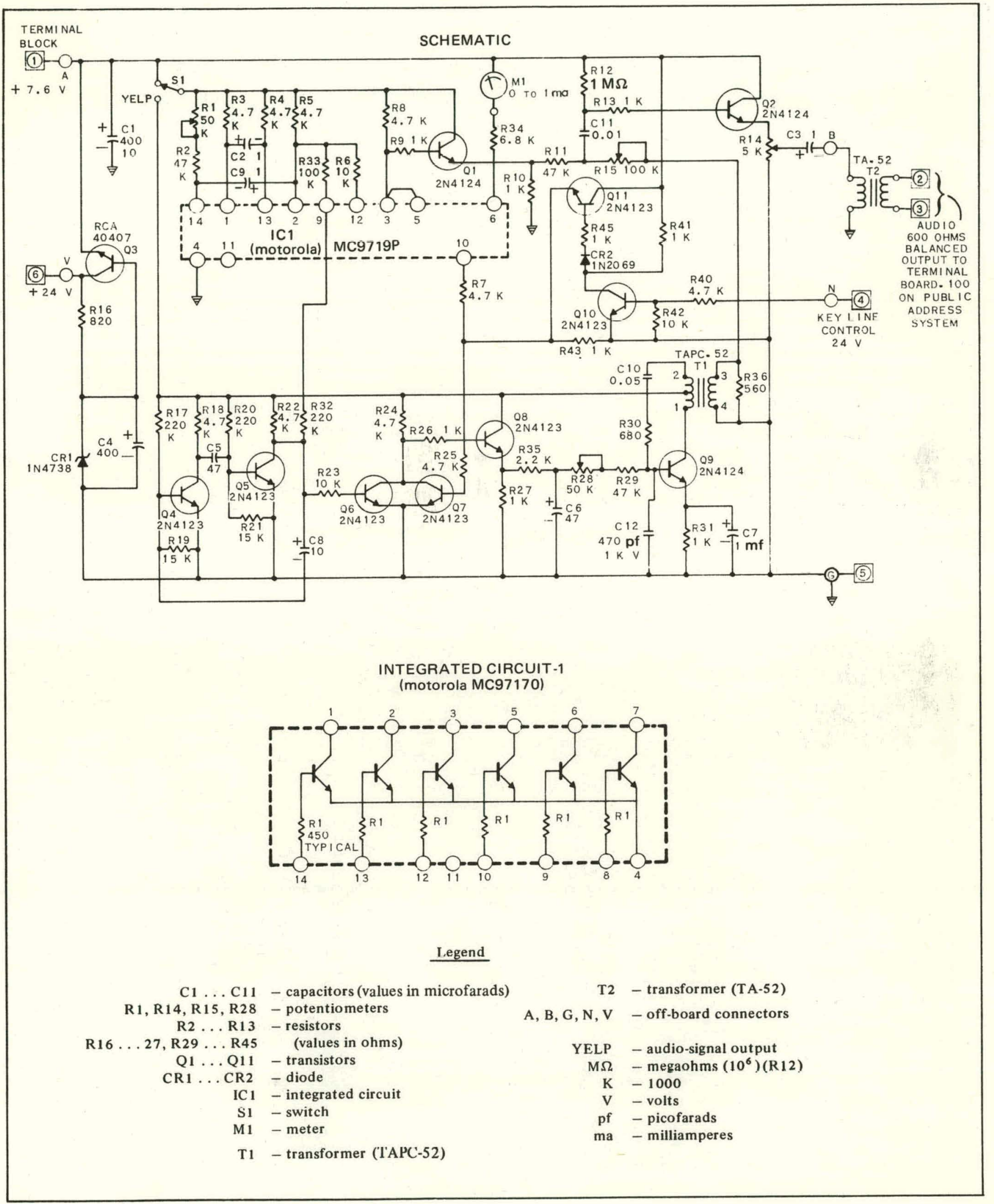




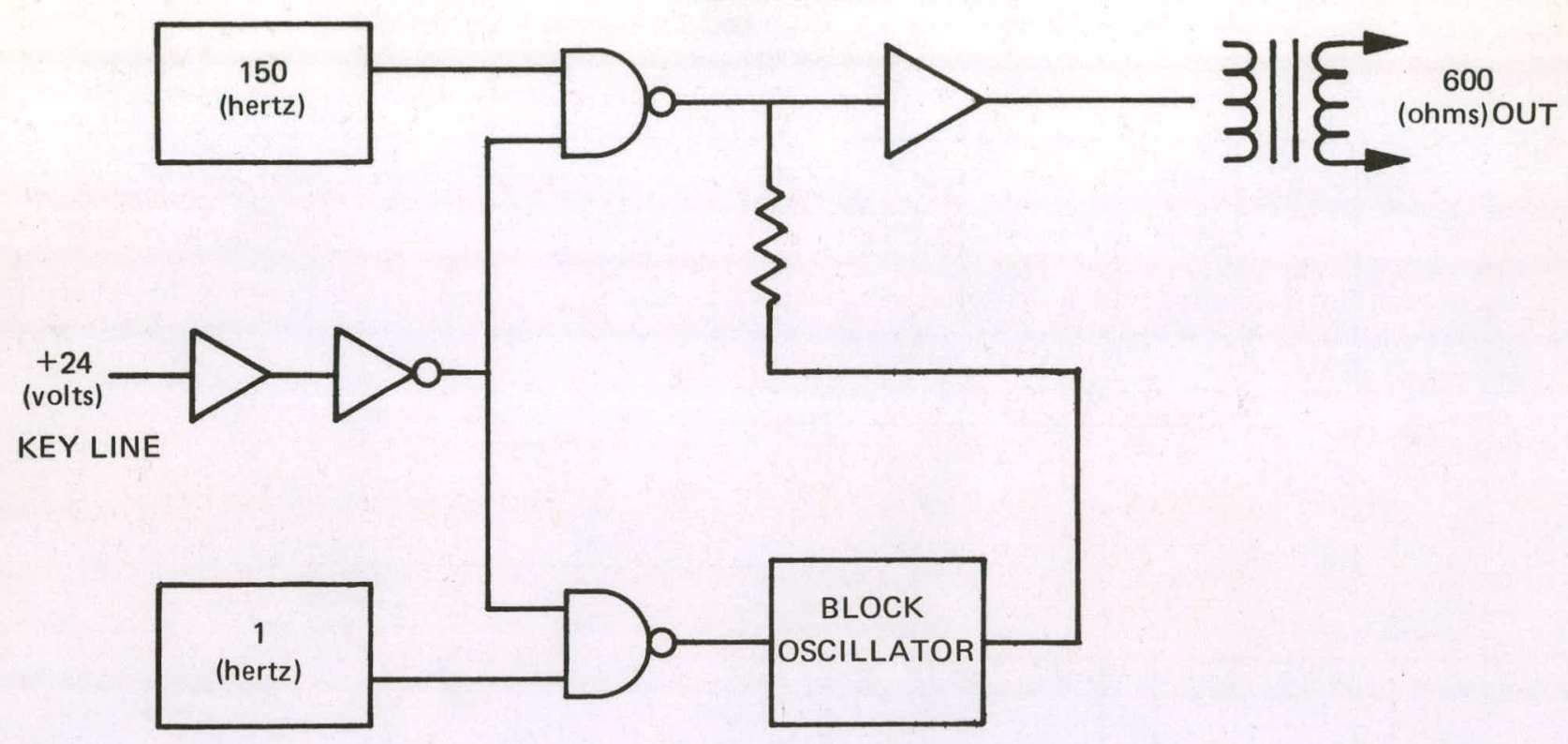

FIGURE 36. Signal Generator Block Diagram.

FIGURE 37. Signal Generator Exterior View.

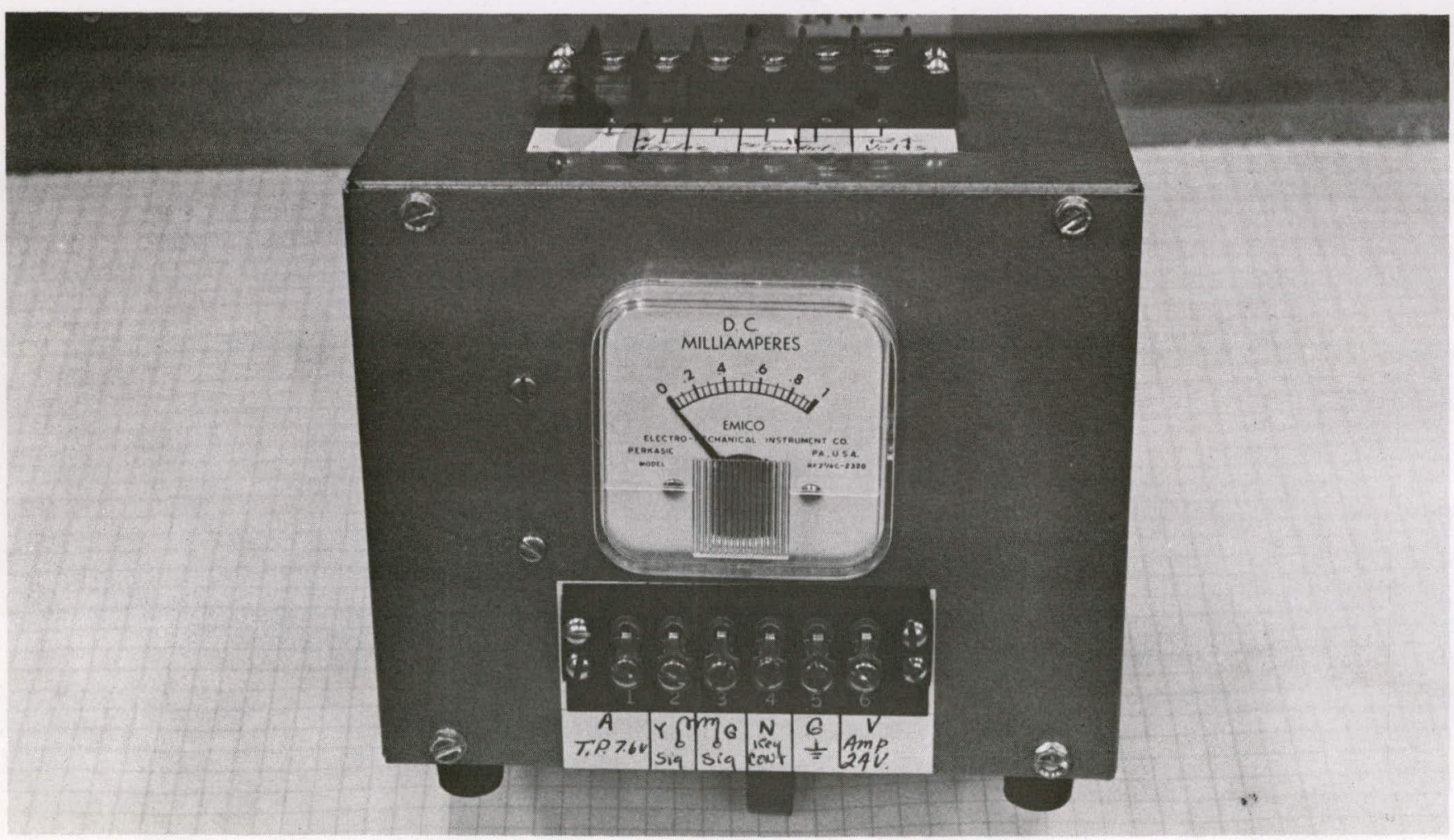




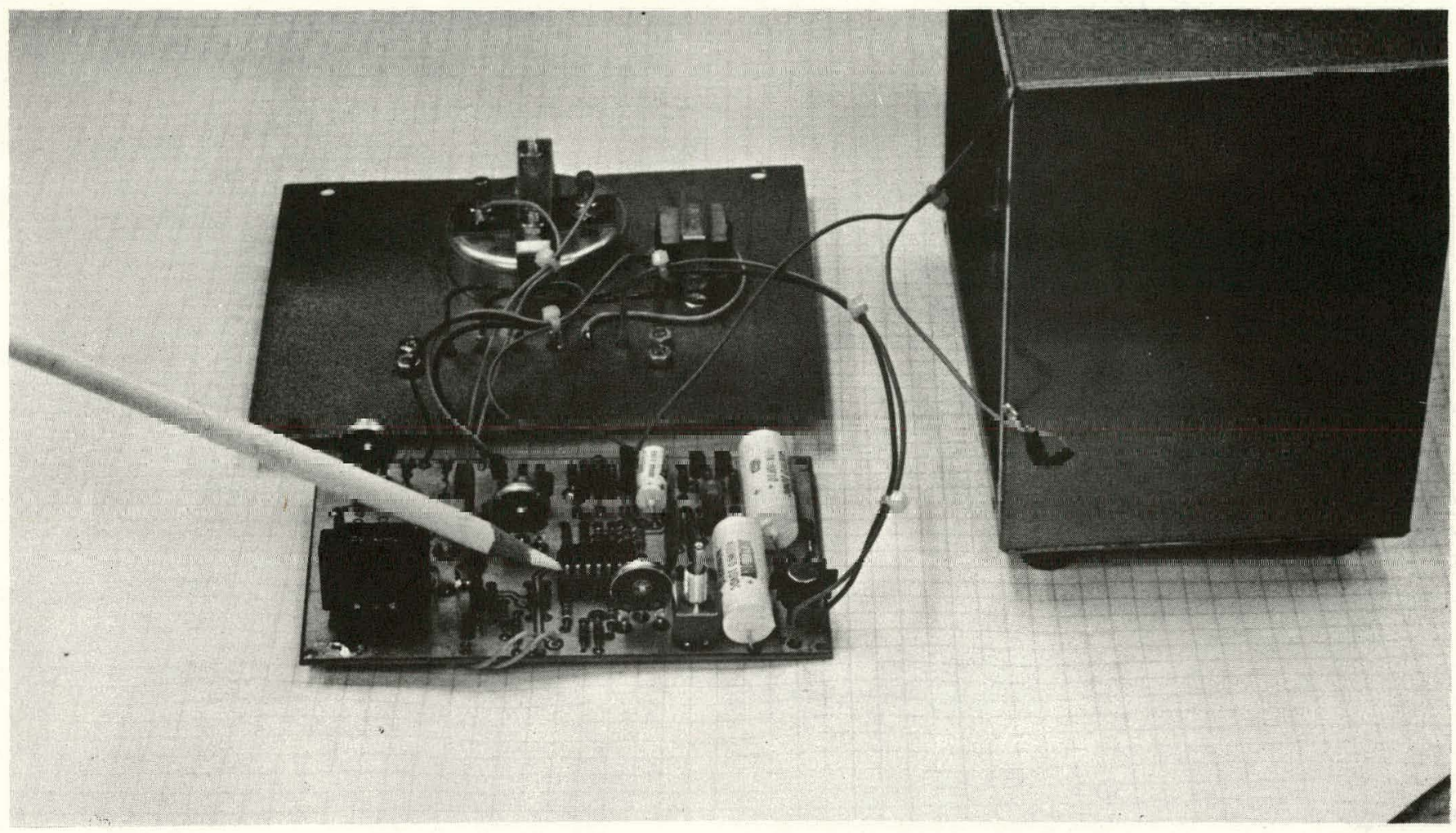

FIGURE 38. Square Wave Generator Portion of Board.

16438-11

FIGURE 39. Warble Generator Portion of Board.

$16438-12$

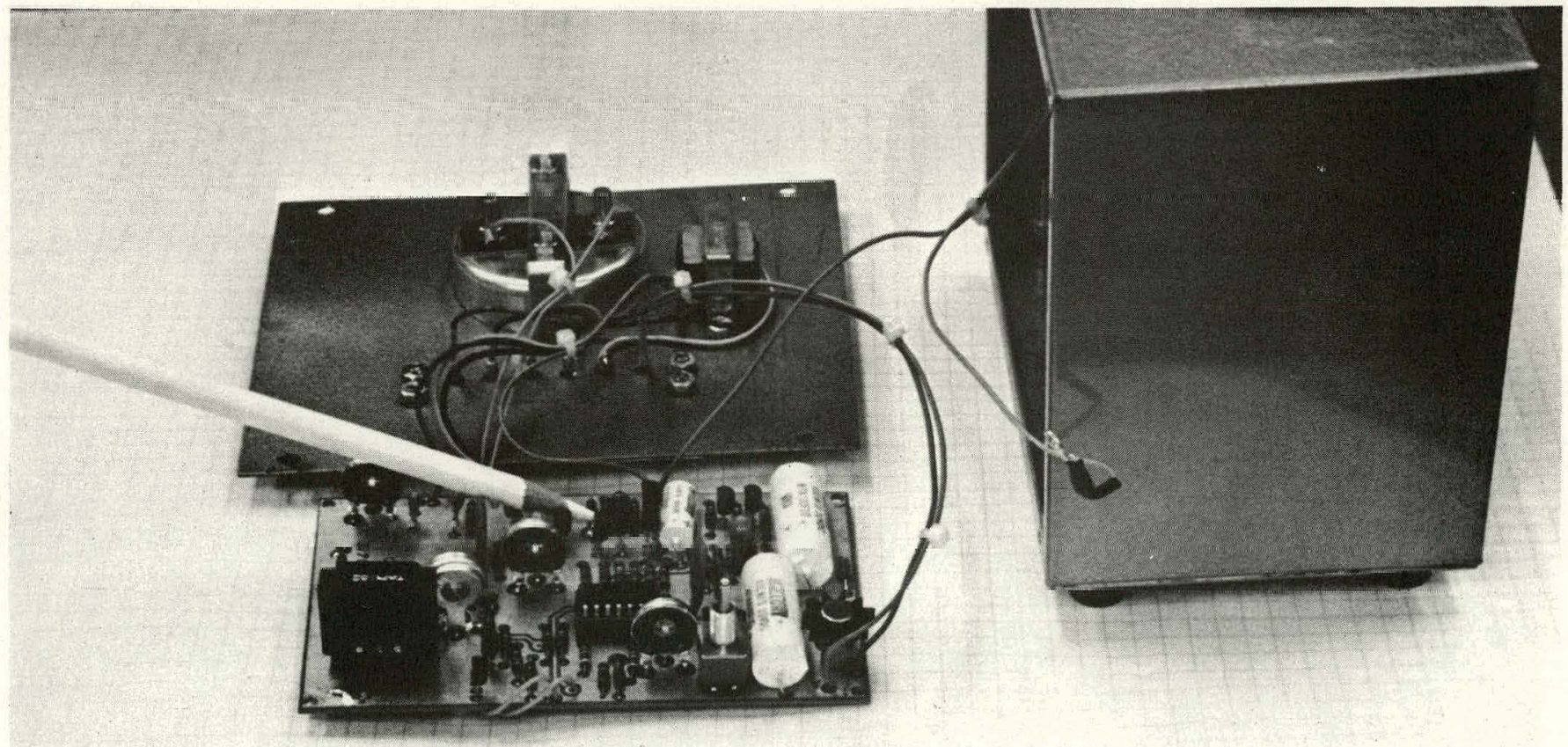




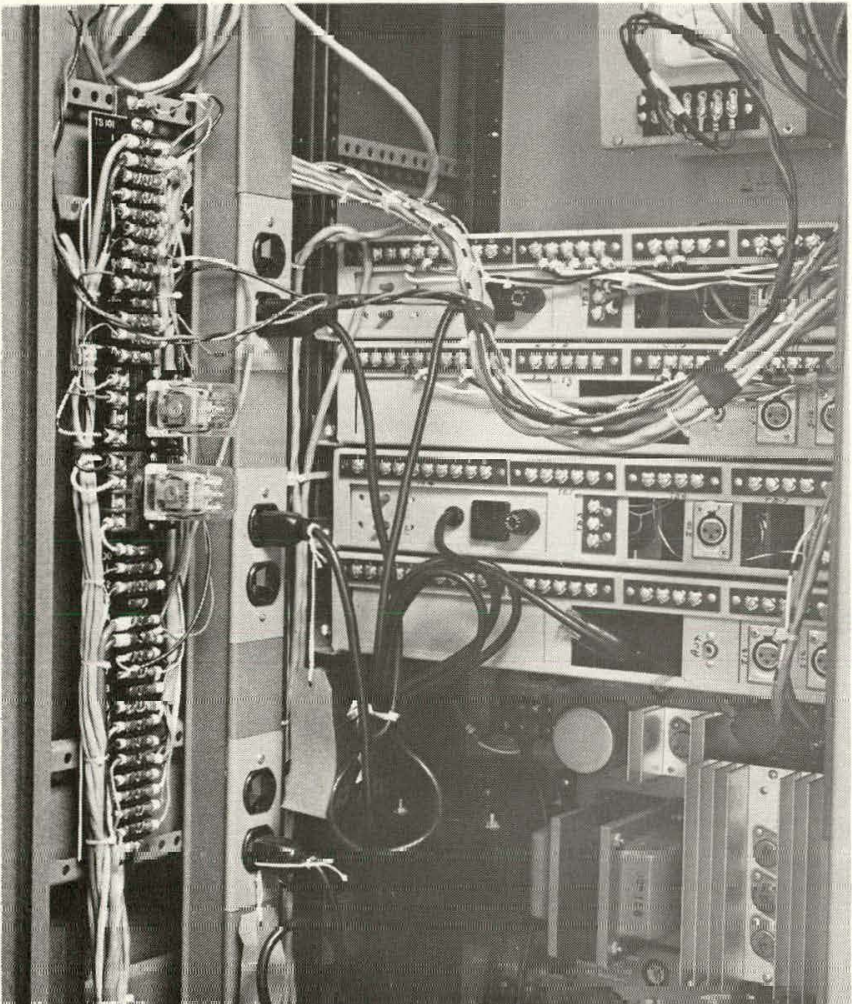

FIGURE 40. Rack-Mounted Signal Generator.

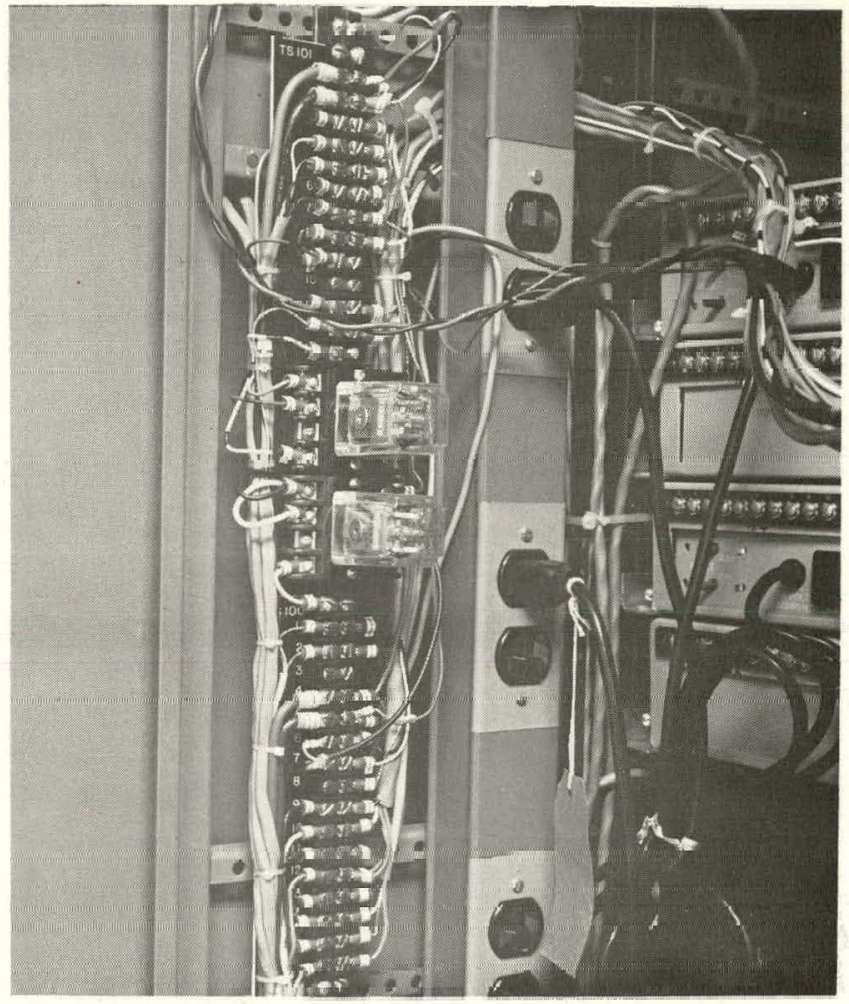

16437-5
FIGURE 41. Rack-Mounted Gener-

$6437-4$

\section{ator, Public Address System Interface.}

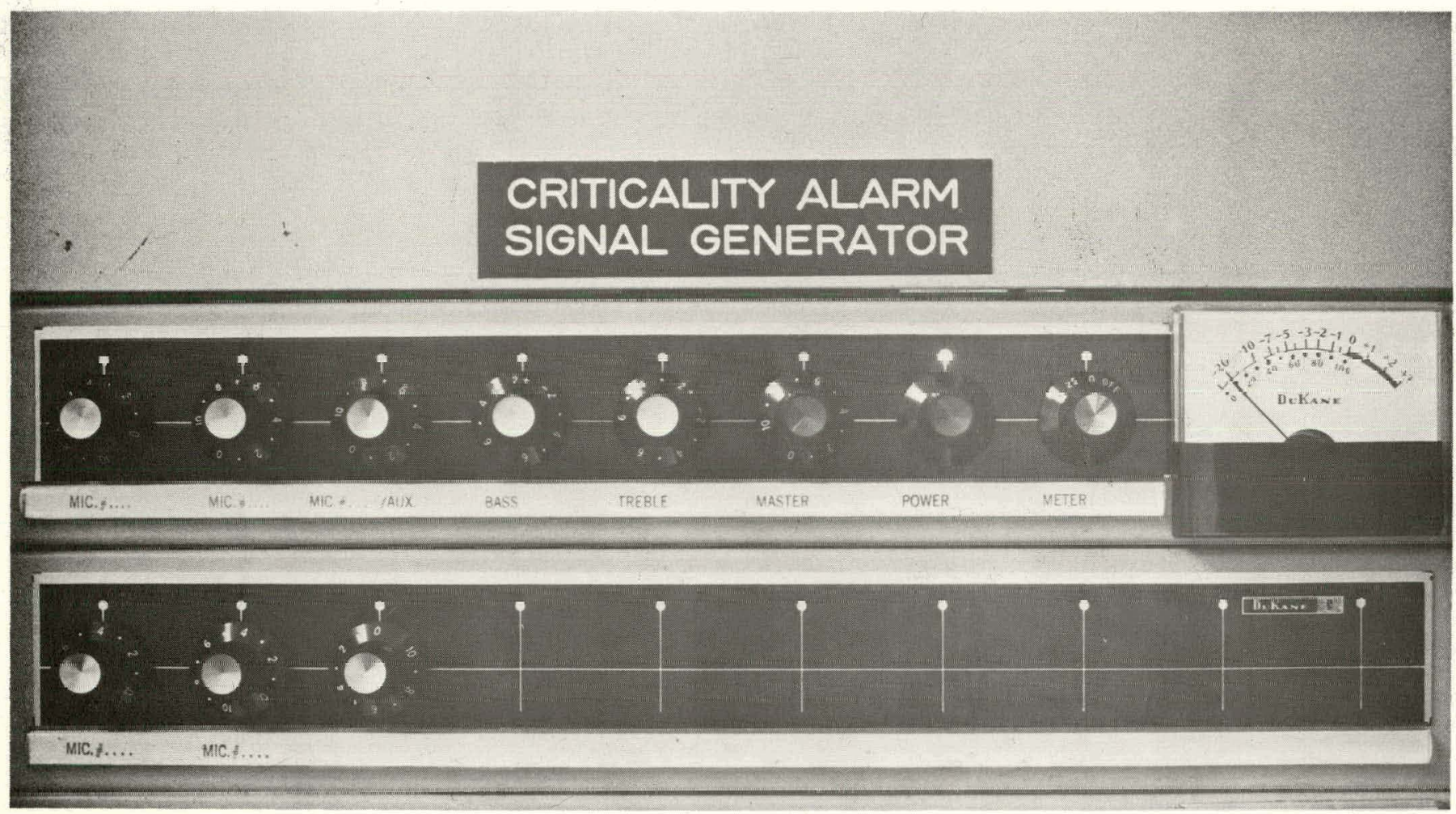




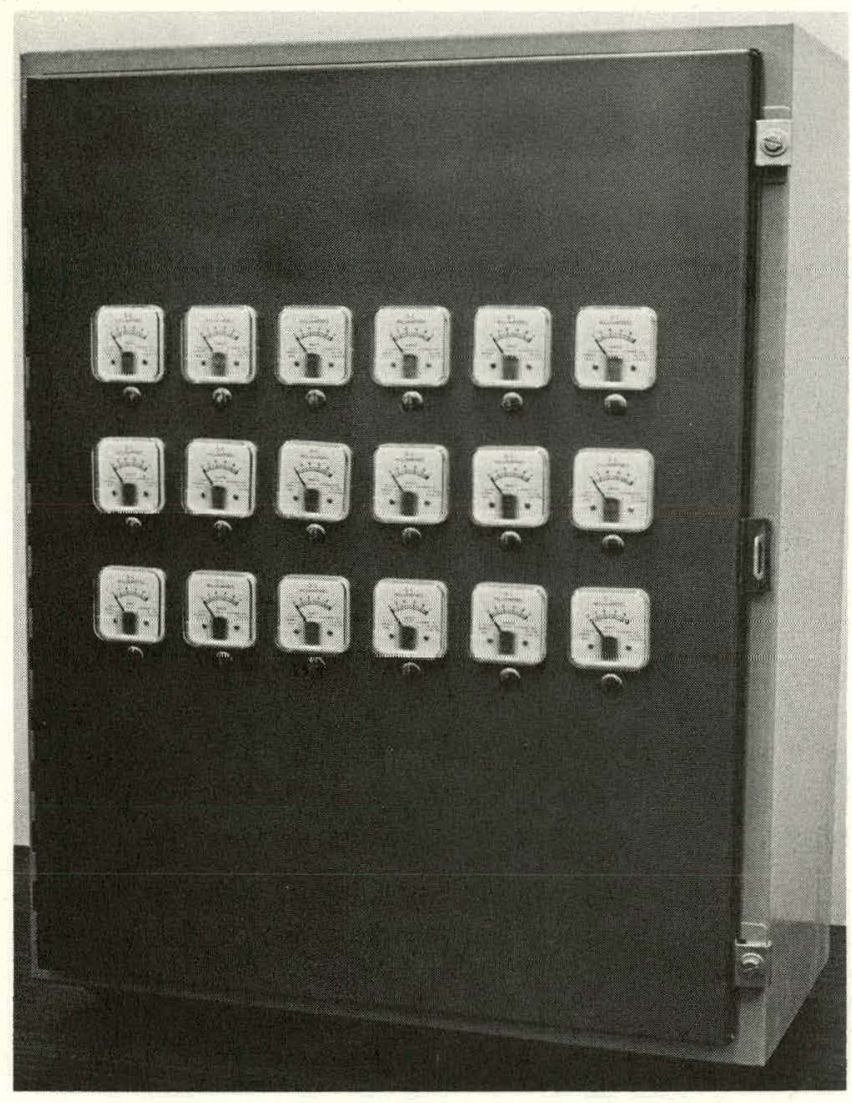

FIGURE 43, Slave Meter Panel (Front).

$16569-1$
FIGURE 44. Slave Meter Panel (Interior).

16569-2

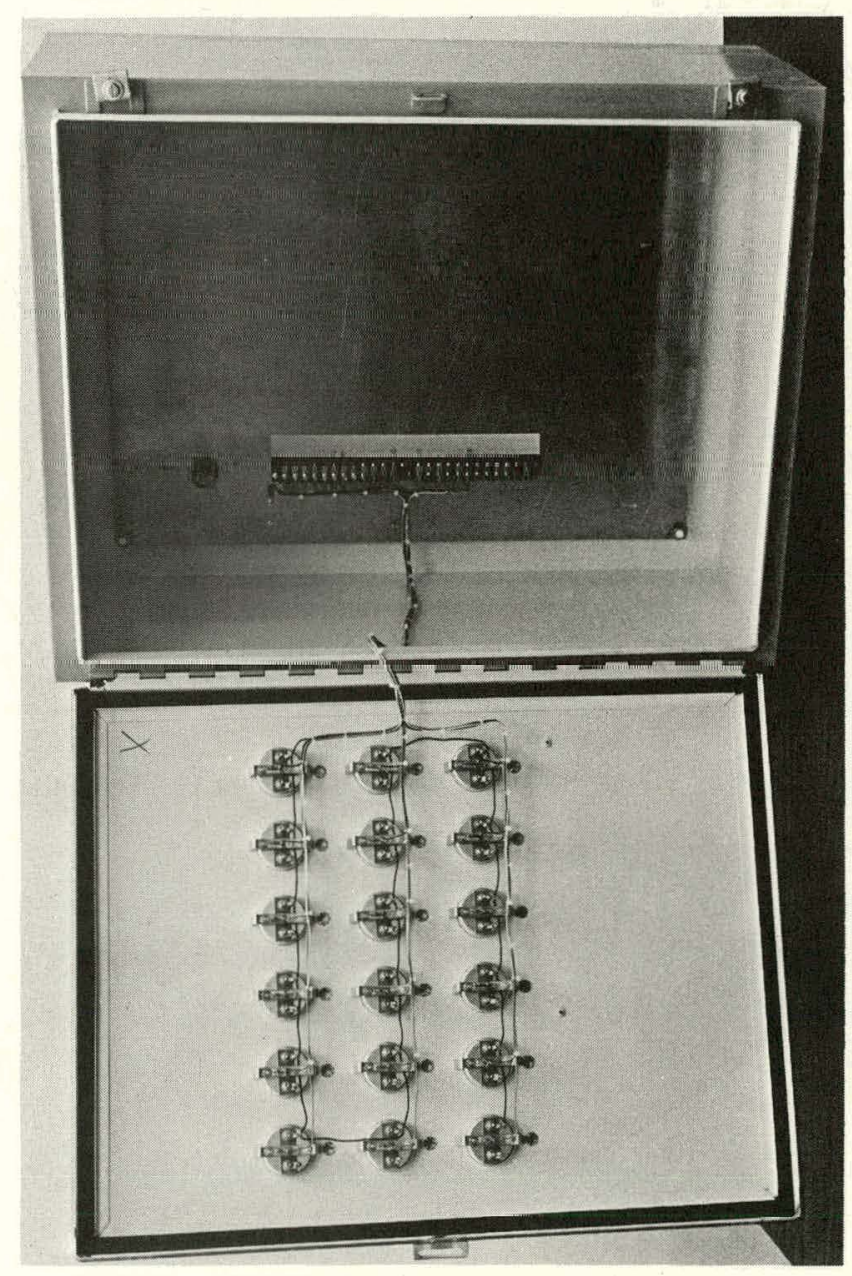


FIGURE 45. Neutron System Interconnections.

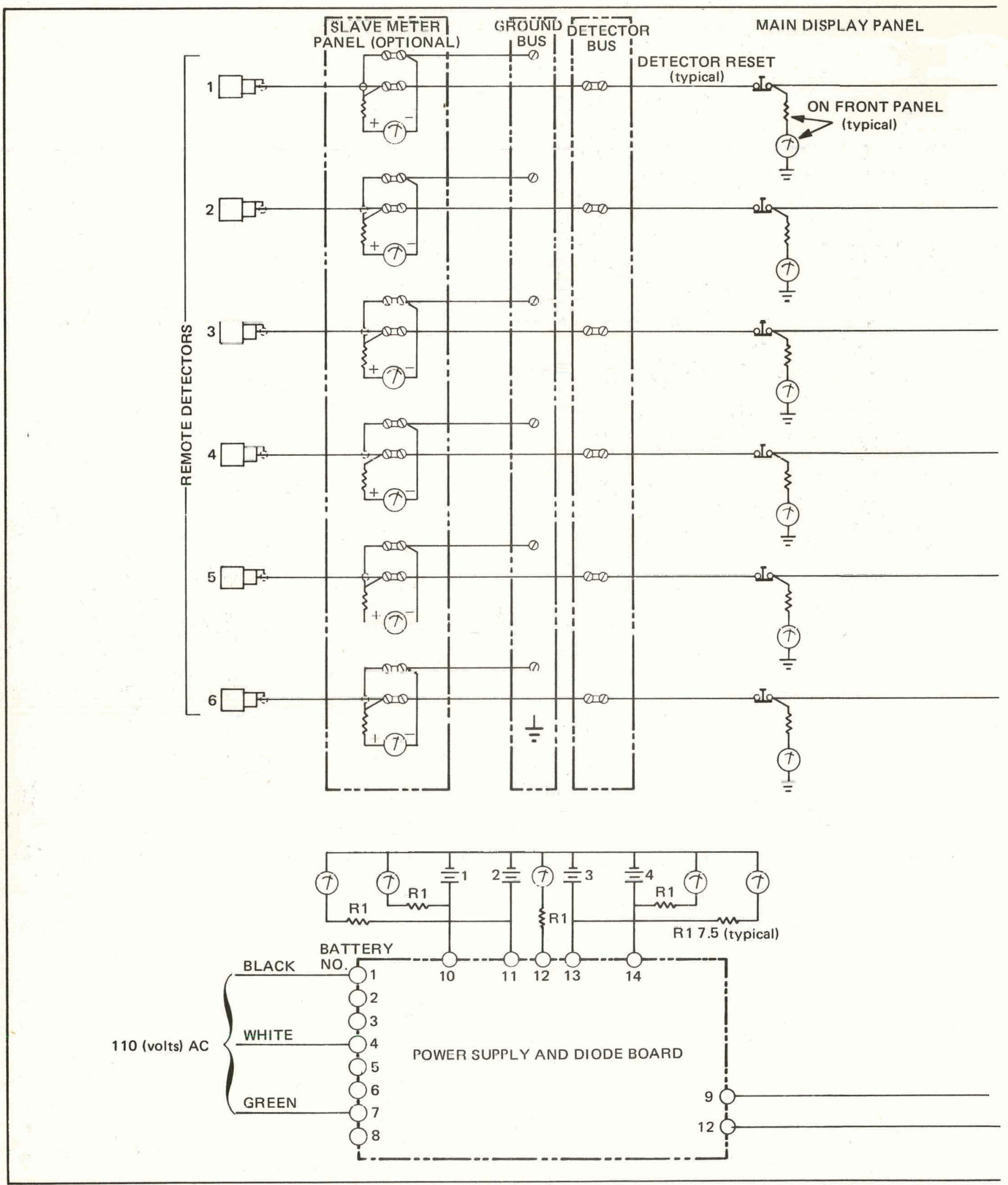


FIGURE 45. (continued).

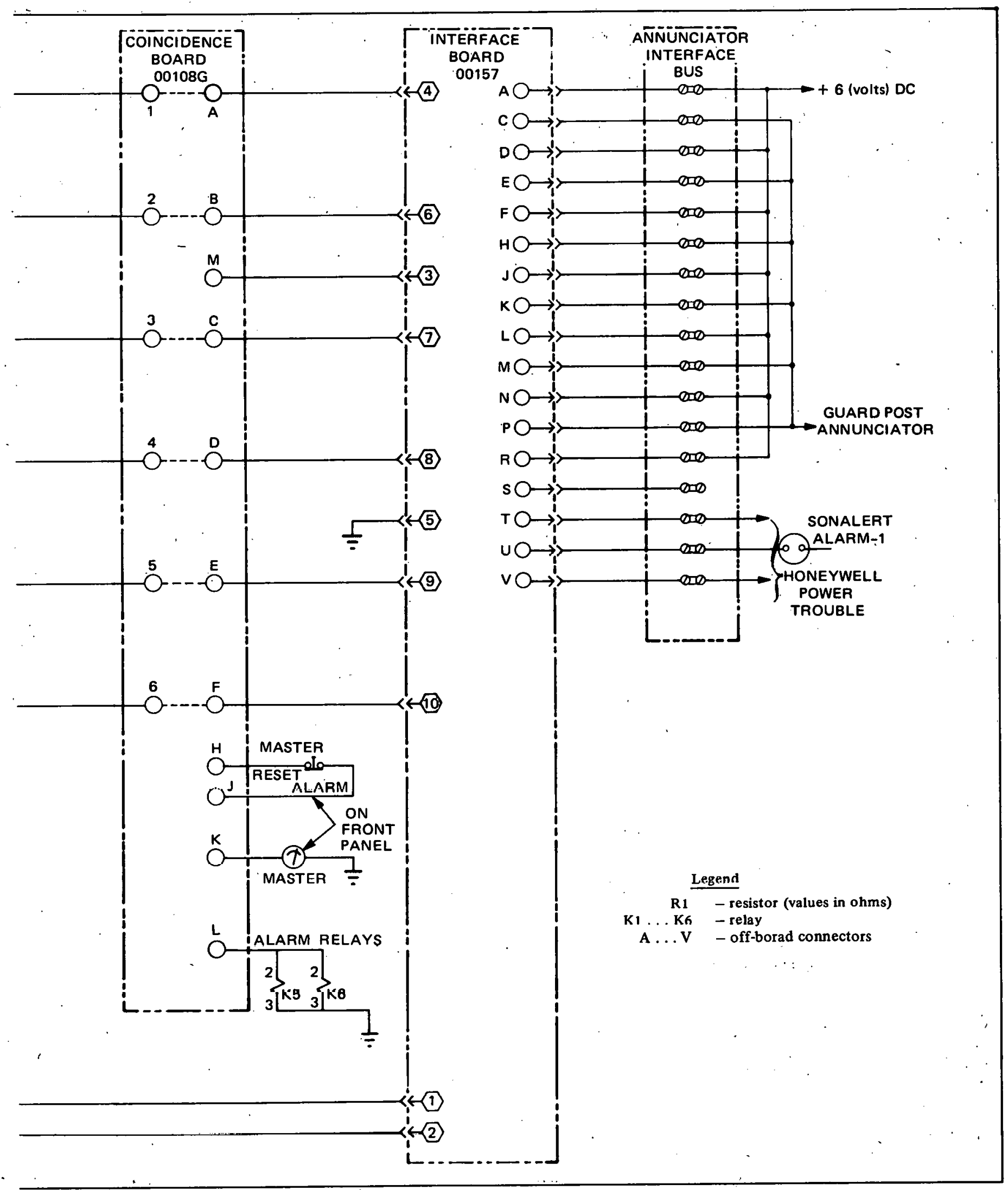


FIGURE 46. Plant Disaster Warning System Interconnections.
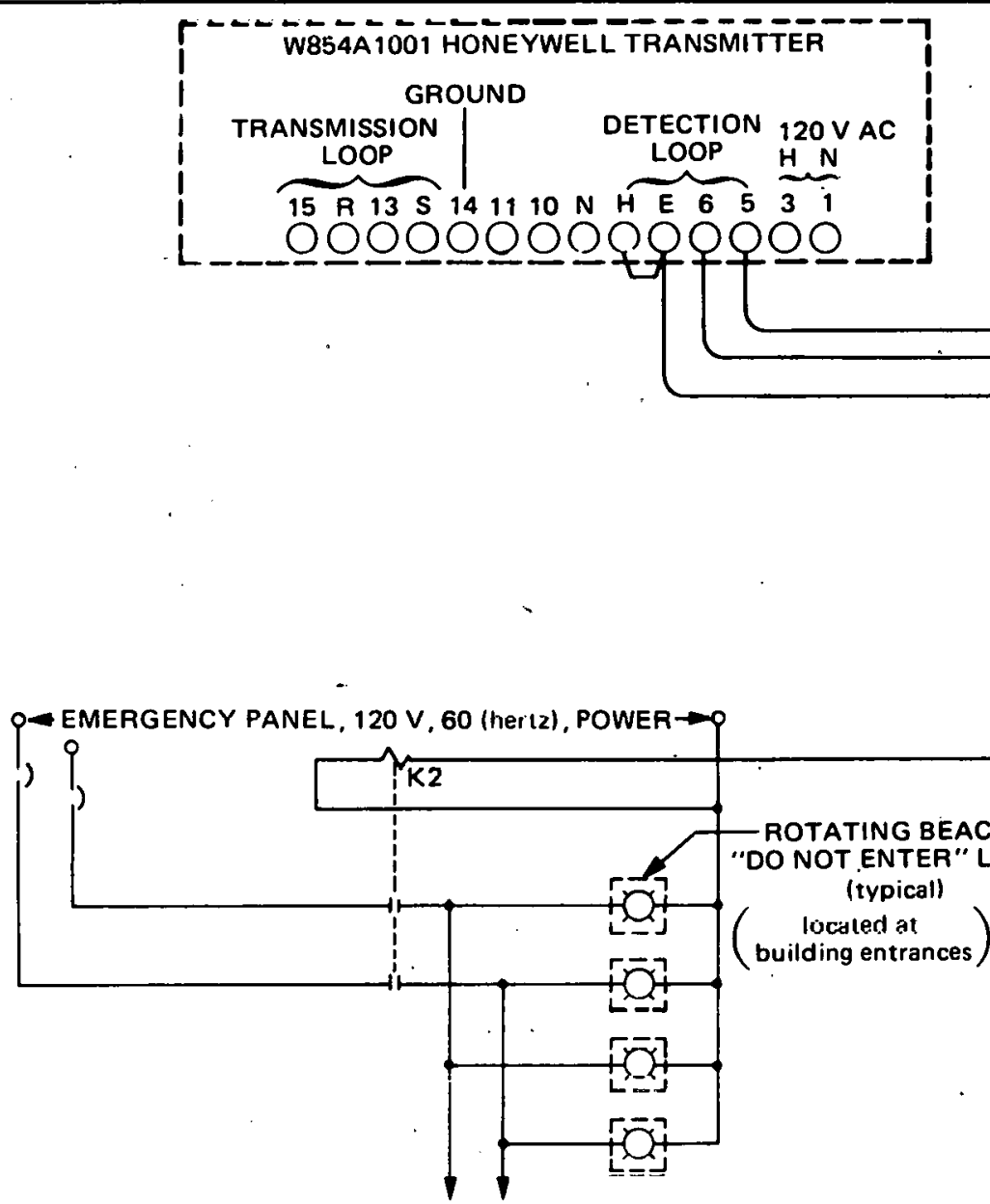

(to every other light)

"DO NOT ENTER" LIGHT SCHEMATIC

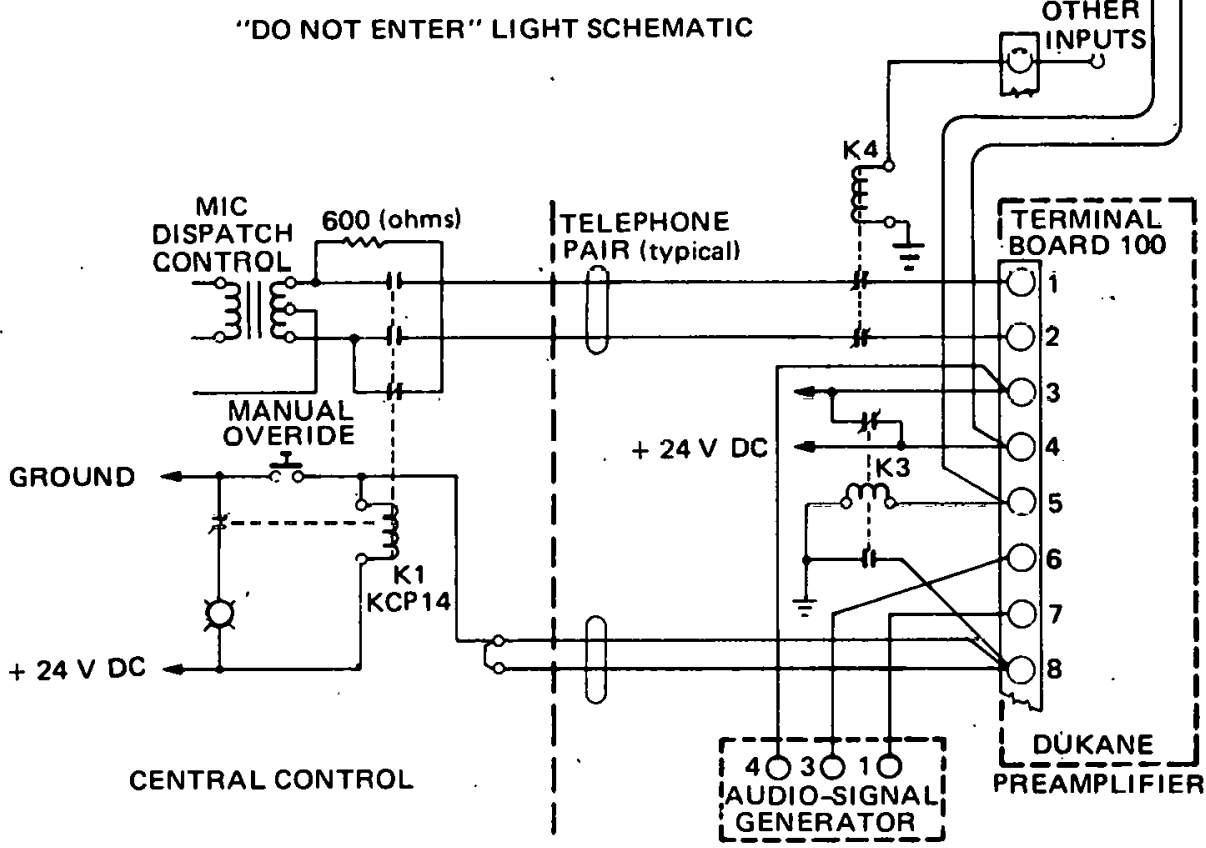


FIGURE 46. (continued).

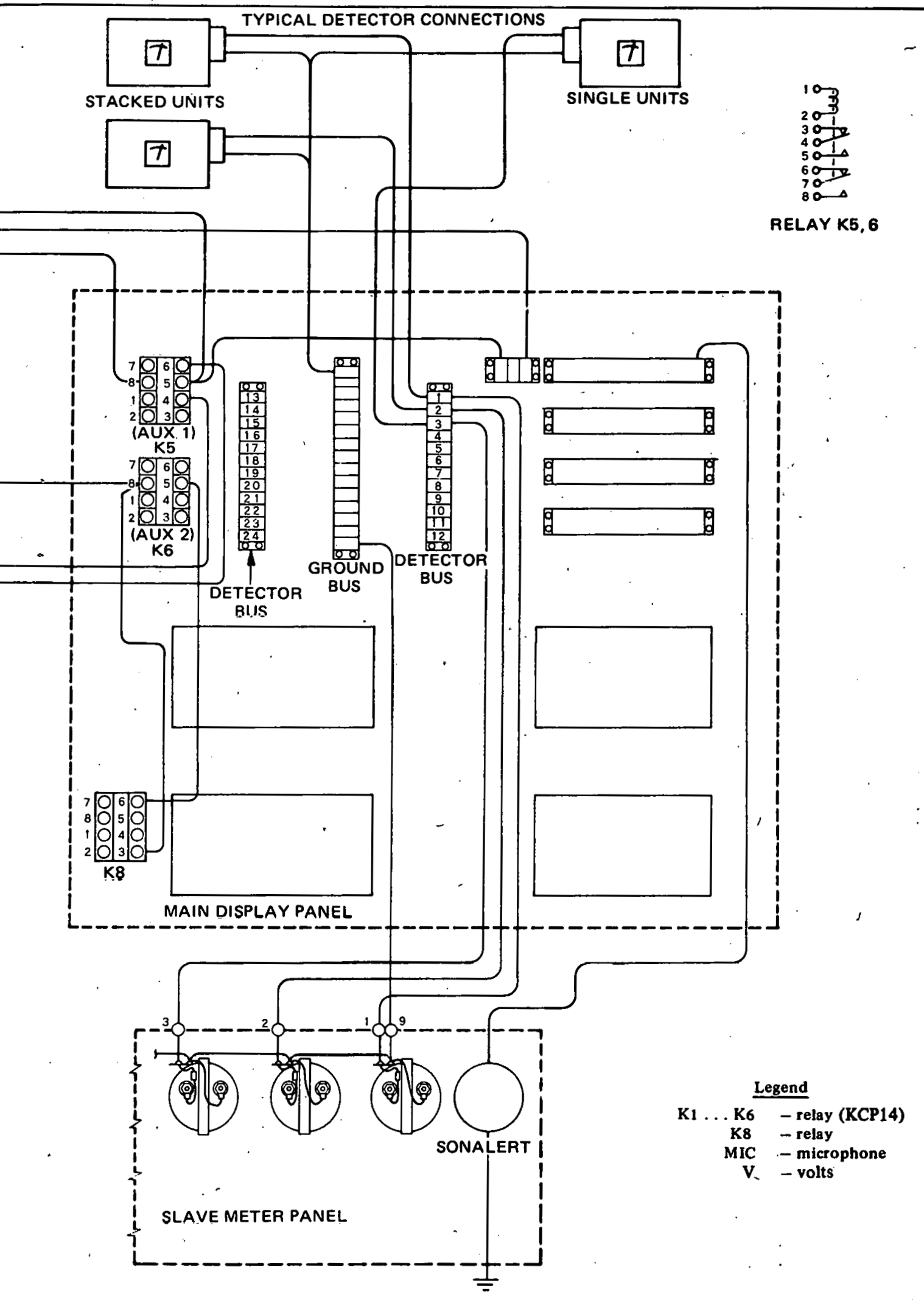

